\title{
Is artificial intelligence an enabler of supply chain resiliency post COVID-19? An exploratory state-of-the-art review for future research
}

\author{
Farheen $\mathrm{Naz}^{1} \cdot$ Anil Kumar $^{2} \cdot$ Abhijit Majumdar $^{3} \cdot$ Rohit Agrawal $^{3}(0)$ \\ Received: 29 June 2021 / Revised: 27 July 2021 / Accepted: 8 August 2021 / Published online: 4 September 2021 \\ (c) The Author(s), under exclusive licence to Springer Science+Business Media, LLC, part of Springer Nature 2021
}

\begin{abstract}
The challenging situations and disruptions that occurred due to the outbreak of the COVID-19 pandemic have created a severe need for supply chain resiliency (SCR). There has been a growing interest among researchers to investigate the resiliency in supply chain operations to overcome risks and disruptions and to achieve successful project management. The supply chain of every business requires innovative projects to accomplish competitive advantage in the market. This study was conducted to identify the significance of artificial intelligence (AI) for creating a sustainable and resilient supply chain, and also to provide optimum solutions for supply chain risk mitigation. A systematic literature review has been conducted to examine the potential research contribution or directions in the field of AI and SCR. In total, 162 articles were shortlisted from the SCOPUS database in the chosen field of research. Structural Topic Modeling (STM), a big data-based approach, was employed to generate several thematic topics of AI in SCR based on the shortlisted articles, and all topics were discussed. Furthermore, the bibliometric analysis was conducted using R-package to investigate the research trends in the area of AI in SCR. Based on the conducted review of literature, a research framework was proposed for AI in SCR that will facilitate researchers and practitioners to improve technological development in supply chain firms. The purpose is to combat sudden risks and disruptions so that project management will perform well Post COVID-19. The study will be also helpful for future researchers and practitioners to identify research directions based on existing literature covered in this paper in the field of SCR. Future research directions are proposed for AI-enabled resilient supply chain management. This study will also provide several implications for supply chain managers to achieve the required resilience in their supply chains post COVID-19 by focusing on the elements of the proposed research framework.
\end{abstract}

Keywords Artificial intelligence $\cdot$ Supply chain $\cdot$ Resiliency $\cdot$ STM $\cdot$ Project management $\cdot$ COVID-19 $\cdot$ Text mining $\cdot$ Big data analytics

Rohit Agrawal

mailerrohit@gmail.com

Farheen Naz

farheen.naz@phd.uni-szie.hu

Anil Kumar

A.Kumar@londonmet.ac.uk

Abhijit Majumdar

majumdar@textile.iitd.ac.in

1 Institute of Economics, Hungarian University of Agriculture and Life Sciences, Godollo, Hungary

2 Guildhall School of Business and Law, London Metropolitan University, London, UK

3 Department of Textile and Fibre Engineering, Indian Institute of Technology, Delhi, New Delhi 110016, India

\section{Introduction}

The coronavirus (COVID-19) outbreak has not only brought global tragedy to human lives, but has also affected business and economic activities, for instance, manufacturing processes, logistics and supply chains, hospitality, and many other (Golan et al. 2020). COVID-19 has challenged scholars and practitioners for the smooth flow of process, as this pandemic became one of the most severe supply chain disruptions in history (Spieske and Birkel 2021). These disruptions, either human-caused or natural, are an integral part of all supply chains globally, irrespective of the nature of goods or services provided or the niche market in which these supply chains operate (Golan et al. 2020). Most companies all over the world face tremendous challenges at every stage of 
their supply chains. Delivery obligations that are not met by suppliers, unpredictable customer demands, and panic buying are some of the challenges faced by the companies (Ivanov 2020). These risks and disruptions created the need to improve the resilience of supply chains to face such types of sudden risks and disruptions. In addition, the change in the market environment is forcing businesses to frequently update their processes and products (Haus-Reve et al. 2019). To achieve effective leadership in the market, managing and launching innovation projects become crucial, which make supply chain management (SCM) further complicated (Kwak et al. 2018). Also, digital transformation leads to several technological developments in the supply chain (Kwak et al. 2018), and for this reason, project management becomes vital for SCM (Gaudenzi and Christopher 2016). Likewise, Shishodia et al. (2019) in their study emphasized a project-driven supply chain which is a combination of both project management and supply chain and requires coordination among on-site project activities and off-site supply chain processes.

Furthermore, some negative consequences lead to low company performance, which involve delays in deliveries, share losses in sales and market, and decrease in service level and consumer satisfaction, all of which directly affect the image of the company (Kara et al. 2020; Spieske and Birkel 2021). These severe negative and unpredictable impacts forces supply chain resilience (SCR) to be the focus of the companies and scholars (Reeves and Whitaker 2020). To improve the SCR, companies should expand analytical capabilities by efficiently applying the resident company knowledge, thus improving the existing information capabilities of the organization (Wong et al. 2020). As far as artificial intelligence (AI) enabled technology is concerned, prior studies have proven that algorithms offer solutions by promoting innovations to improve supply chain performance (SCP) (Baryannis et al. 2019a; Nayal et al. 2021). According to Ivanov et al. (2019), emerging technologies like industry 4.0, AI, product tracking advanced applications, and additive manufacturing have considerable potential for supply chain risk analytics, thus strengthening SCR and managing projects. Integration of advanced technologies makes the supply chain resemble large-scale projects to coordinate and manage several activities, that enables smooth project management (Gaudenzi and Christopher 2016). Wei et al. (2021) clarified that the increasing complexity of project management and SCM inclusion in it makes it critical for project managers to manage and coordinate requirements by adopting the best approach. For instance, it is advantageous in the ship building industry to integrate project management information systems along with SCM, where time-phased requirements are managed by project management and supply chain issues are tackled by SCM (Braglia and Frosolini 2014).
As far as SCR is concerned, its main objective is to quickly regain from supply chain disruptions and to improve the original performance of the supply chain (Ponomarov and Holcomb 2009). The impact of any disruption intensifies as supply chains have become more complex in a global context (Kwak et al. 2018). Thunberg et al. (2017) stated that project management processes and supply chain are interlinked and often affect each other. In this regard, supply chain performance could be enhanced through adaptation capabilities and information processing offered by AI techniques (Belhadi et al. 2021a). Similarly, for successful projects, AI was applied in several sectors to improve flexibility, communication, and reducing unnecessary fluctuations (Lalmi et al. 2021). In recent years, AI applications have developed due to the growing computing power availability, growth in machine learning approaches, and big data analytics. This has led supply chain researchers to consider the potential of AI techniques in terms of risk identification, assessment, prediction, and response (Baryannis et al. 2019b). To overcome the impact of risks and disruptions, Katsaliaki et al. (2021) suggested that it is necessary to build resilience by integrating three aspects, i.e., long-term partnerships, IT applications to enhance business, and government policies that facilitate flexibility.

Furthermore, the COVID-19 outbreak has attracted a lot of attention from scholars to build SCR (Kumar and Anbanandam 2020) and project management agility (Bushuyev et al. 2020). Creating agility in large-scale projects through adaptation of various strategies will develop SCR, if the project processes are managed at an early stage (Thunberg et al. 2017). Also, the short-term direct impact of AI on SCR has been noticed, and it is proposed to utilize its capability of processing information to build SCR, thereby improving long-term SCR (Belhadi et al. 2021a). This can be done by deploying emerging technologies in the entire supply chain network (Ivanov et al. 2019) and managing projects thereby. For this purpose, the current study was conducted to analyse the significance of AI in SCR post COVID-19. The disruptions caused by the COVID-19 pandemic in the entire supply chain and project management created a need for a robust literature review in the related field to analyse the existing problems and solutions. The studies involved in this paper were conducted before and during the COVID19 pandemic, hence it provides relevant evidence of $\mathrm{AI}$ in SCR. It is crucial to better understand the relevance and practical implication of existing AI-based models to solve issues concerning SCR that exists during or post COVID-19 disruptions. To the best of the authors' knowledge, this study is the first attempt to show the role of AI in SCR during or post COVID-19 pandemic. For this, a systematic review was presented by collecting articles in the field of AI and SCR. To gather papers, the SCOPUS database was used by using relevant keywords in AI and SCR. 162 articles were 
chosen to perform the systematic review. First, the structural topic modeling (STM) based text mining approach was used to produce thematic topics. Secondly, based on the generated thematic topics, the shortlisted articles were reviewed. Then, the bibliometric study was performed to examine the research trends in the fields of AI and SCR. Finally, a conceptual framework was suggested which incorporates $\mathrm{AI}$ and SCR practices. The following research questions are formed to answer in this study:

$R Q 1$. What are the AI techniques that could help make a resilient supply chain?

$R Q 2$. What are the current research trends associated with $\mathrm{AI}$ in SCR?

$R Q 3$. What are the potential future research directions in $\mathrm{AI}$ in SCR?

This study starts with a systematic literature review to answer the above questions. To generate the topics, an STM-based text mining technique was employed. Various aspects of AI and SCR were explored and several AI techniques were investigated to adopt for SCR and risk mitigation. To analyse the research trends, a bibliometric analysis was carried out. Further, a conceptual framework was proposed to provide utilization of AI techniques in the SCR post-COVID-19.

The remaining sections of this article are as follows: Sect. 2 shows the systematic literature review methodology, Sect. 3 shows the bibliometric analysis, Sect. 4 shows the STM approach, whereas the review of articles based on generated topics were presented in Sect. 5. Discussion and implications were presented in Sect. 6, while Sect. 7 shows conclusions of the study.

\section{Systematic literature review}

A systematic review literature methodology was used in this paper to gain comprehensive insights concerning previously conducted studies on SCR and AI. The SLR methodology adopts a replicable, scientific, and transparent procedure that differs from traditional narrative reviews (Tranfield et al. 2003). The current study followed the SLR methodology as conducted by Agrawal et al. (2021). For this purpose, the published articles from the SCOPUS database were collected, as it is among the largest databases which consist of a large number of peer-reviewed articles. Through the SCOPUS database, an SLR was presented by defining keywords and searching articles about selected keywords (Vinodh et al. 2020). The study's SLR is based on the four-stages review approach as depicted in Fig. 1. Moreover, several researchers were involved in this study to prevent individual biases (Tranfield et al. 2003).
In the first stage of this four-stages methodology, retrieval of articles was done based on searching of articles on SCR and AI. The shortlisted keywords were used to collect the articles from the SCOPUS database.

The next stage involved the bibliometric study of the collected articles. For this purpose, the R package and VOSviewer were used. After that, the research fields were analysed concerning the investigating area, which is done by using STM. The STM approach was performed using the $\mathrm{R}$ package to generate ten emerging research fields in SCR and AI. In the third stage, the identified evolving research themes were discussed, and future direction propositions were stated. Finally, in the last stage, a future research framework was proposed, and a conclusion was made based on the results generated.

\section{Bibliometric study}

In recent years, bibliometric analysis has gained massive popularity in the research field of business and management (Donthu et al. 2021). The bibliometric methods are used to provide quantitative analysis of written papers or publications (Ellegaard and Wallin 2015). The analysis is conducted based on the identification of the amount of literature concerning an investigating area. Various statistical tools are used rapidly to perform bibliometric analysis, for instance, R package, Pajek, Histcite, Bibexel, and Gephi (Agrawal et al. 2021).

In business research, the popularity of bibliometric analysis is due to the manifestation of its efficiency to handle large quantity of scientific data and creating high research impact (Donthu et al. 2021). To perform the bibliometric analysis, $R$ package was used.. A web interface of the R package named biblioshiny was employed, allowing users to conduct relevant bibliometric and visual analyses. Biblioshiny is an interactive web interface that greatly reduces the information input intensity of users and usage threshold as well (Xie et al. 2020). Table 1 presented the main information of the shortlisted articles about SCR and AI.

The year-wise publications of the articles in SCR and AI are indicated in Fig. 2. An increasing trend starting from 2005 can be seen in this field of research. However, a rapid increase in this trend was witnessed since 2018 , whereas in 2019 there was an $81 \%$ increase in publications in comparison to 2018.

Figure 3 demonstrates the country-wise number of articles published in SCR and AI. It is apparent from Fig. 3 that the United States is the leading country in terms of publications in this field. Iran and China are in the second and third positions, respectively with significant contributions in the field of SCR and AI. 
Fig. 1 SLR flowchart

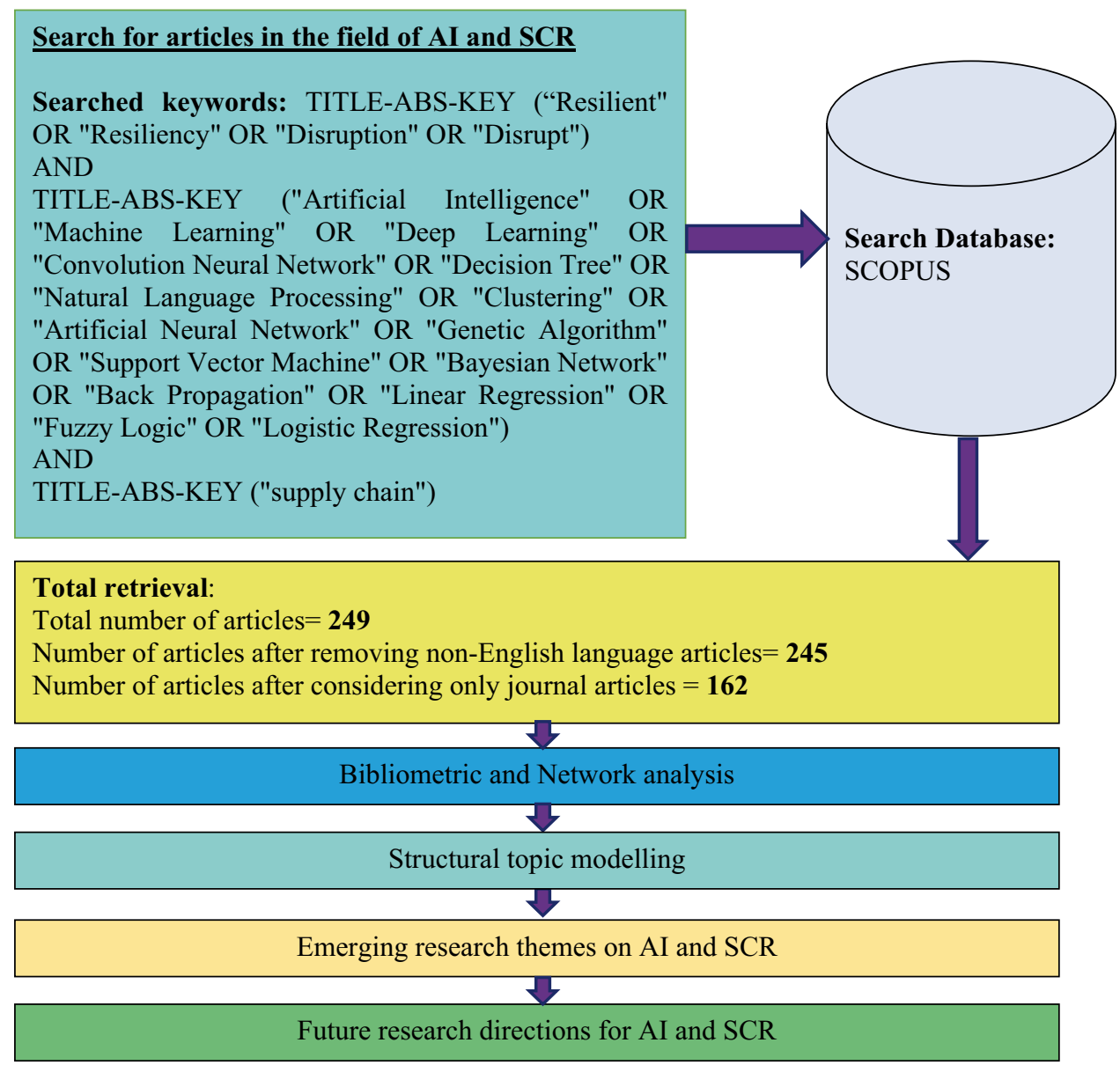

From Fig. 4, it is found that the United States is the leading country in terms of citations received in the field of AI and SCR. It is followed by Iran and UK..

Table 2 shows the top leading journals in the AI and SCR field.

Table 2 depicts that the International Journal of Production Research is the leading journal to publish the most number of articles $(n=16)$ in the field of AI and SCR. However, the other journals are Computers and Industrial Engineering and the International Journal of Production Economics with a significant number of published articles in this field.

As far as the contribution of the authors in this research field is concerned, Table 3 presented the top ten influential authors with a maximum number of published articles in this area. Ivanov D and Hosseini S are two leading authors to contribute to this field of research with 7 and 6 published articles, respectively.

Table 4 represents the top ten organizations contributing to the research field of SCR and AI. Among these organizations, Islamic Azad University, Iran is the leading organization to publish 11 articles in this area. This is followed by the Berlin School of Economics and law, Iran University of Science and Technology, and the University of Southern Mississippi with 6 published articles, each.

In Table 5, the occurrence of top keywords in the field of SCR and AI are shown. It shows that the keyword 'supply chains' occurred 80 times in the search for the articles concerning the studied area. It is followed by 'supply chain management' and 'decision making' that occurred 42 and 33 times, respectively. Table 5 shows 20 such keywords and their occurrences in the field of AI and SCR. Figure 5 depicts the 'word cloud' of the keywords present in the abstracts of the articles and highlights the most common words available in the database. Consequently, the size of the word represents the occurrence of the keyword in selected articles. As depicted in Fig. 5 that the keywords of this study are supply chains, SCM, and AI, which are at the center of the map. These keywords occurred multiple times in the selected articles and were constant throughout the research.

Network analysis was carried out to understand how countries and authors have collaborated based on coauthorship. For this purpose, the VOS viewer package was used to examine the collaboration network among countries as well as among authors. A total of 162 articles were considered in this study and there are 464 authors in the 
Table 1 Main information collected about AI and SCR articles

\begin{tabular}{ll}
\hline Description & Results \\
\hline Main Information About Data & \\
Timespan & $2005: 2021$ \\
Sources (Journals, Books, etc.) & 107 \\
Documents & 162 \\
Average years from publication & 3.51 \\
Average citations per documents & 20.27 \\
Average citations per year per doc & 4.243 \\
References & 9078 \\
Document Types & \\
Article & 152 \\
Review & 10 \\
Document Contents & \\
Keywords Plus (ID) & 1046 \\
Author's Keywords (DE) & 557 \\
Authors & \\
Authors & 464 \\
Author Appearances & 522 \\
Authors of single-authored documents & 10 \\
Authors of multi-authored documents & 454 \\
Authors Collaboration & \\
Single-authored documents & 11 \\
Documents per Author & 0.349 \\
Authors per Document & 2.86 \\
Co-Authors per Documents & 3.22 \\
Collaboration Index & 3.01 \\
\hline
\end{tabular}

considered articles. We made a cluster by considering all authors. Figure 6 shows the authors collaboration network in the field of AI and SCR. From the authors' collaboration network, we can see that 6 clusters were formed which includes 27 authors while other authors are removed due to low connectivity of them with other authors. The figure shows six different networks where the size of the nodes depicts the number of collected publications, whereas the colour of the nodes represents the cluster in which these publications belong. The developed network has six clusters with 52 links and 56 total link strengths. The red cluster is the largest cluster with seven authors, whereas the green, blue, and yellow clusters have five authors each. The sixth cluster is the smallest one which includes only three authors. The author collaboration network also shows that the author Ivanov D has the maximum connection with other authors with a total of 12 links and the total link strength is 15 .

The country-wise collaboration network is presented in Fig. 7. It shows the collaboration of different countries with each other to conduct research related to SCR and AI. A total of 55 countries is involved in the publication of the 162 articles. We made a cluster by considering all countries. From the country collaboration network, we can see that eight clusters were formed which include 33 countries while other countries are removed due to low connectivity of them with other countries. The United States and Iran have contributed significantly to the research field of AI and SCR and have published a considerable number of scientific research in this area. The developed network has eight clusters with 69 links and 91 total link strengths. The top five clusters (red, green, dark blue, yellow, and violet) have five countries each whereas the brown cluster is the smallest one which includes only two countries. The country collaboration network also shows that the country United States has the maximum connection with other countries with a total of 16 links and total link strength of 26. Based on the network analysis, the United States, China, and the United Kingdom can be considered as the core countries of this network as they established collaborated research with all other top countries researching SCR and AI.
Fig. 2 Year-wise publication of articles in the field of AI in SCR

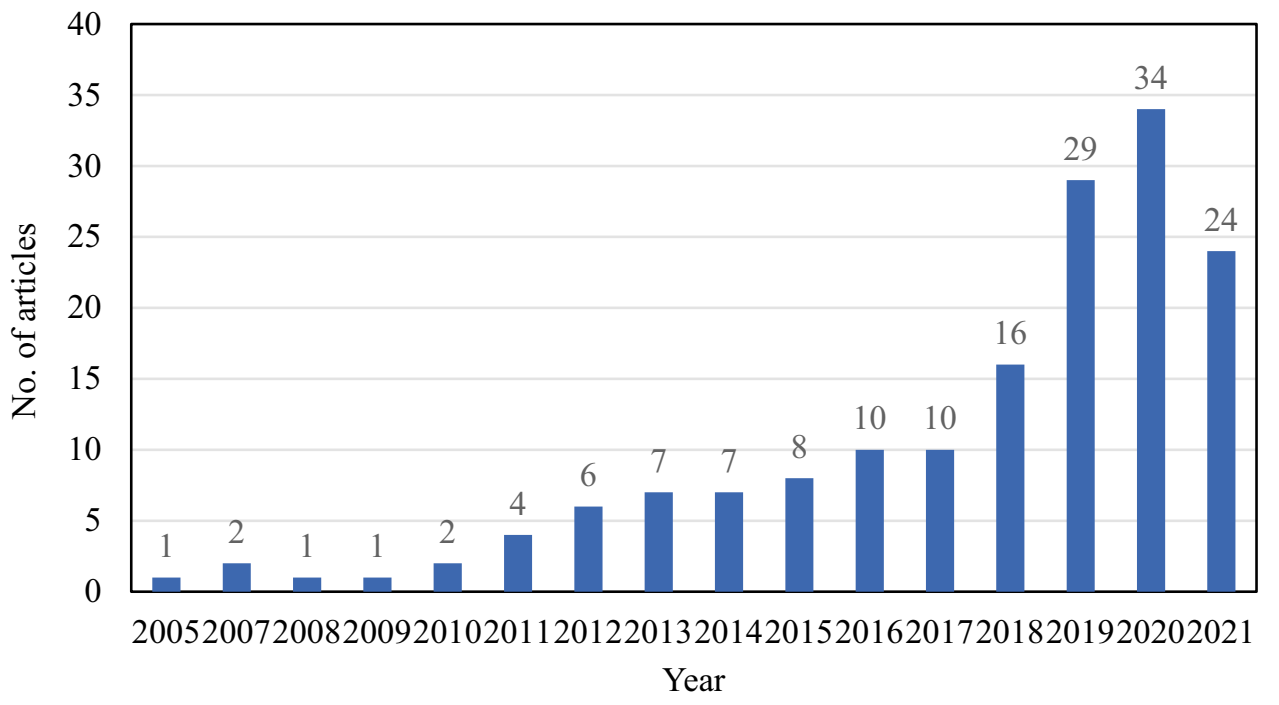




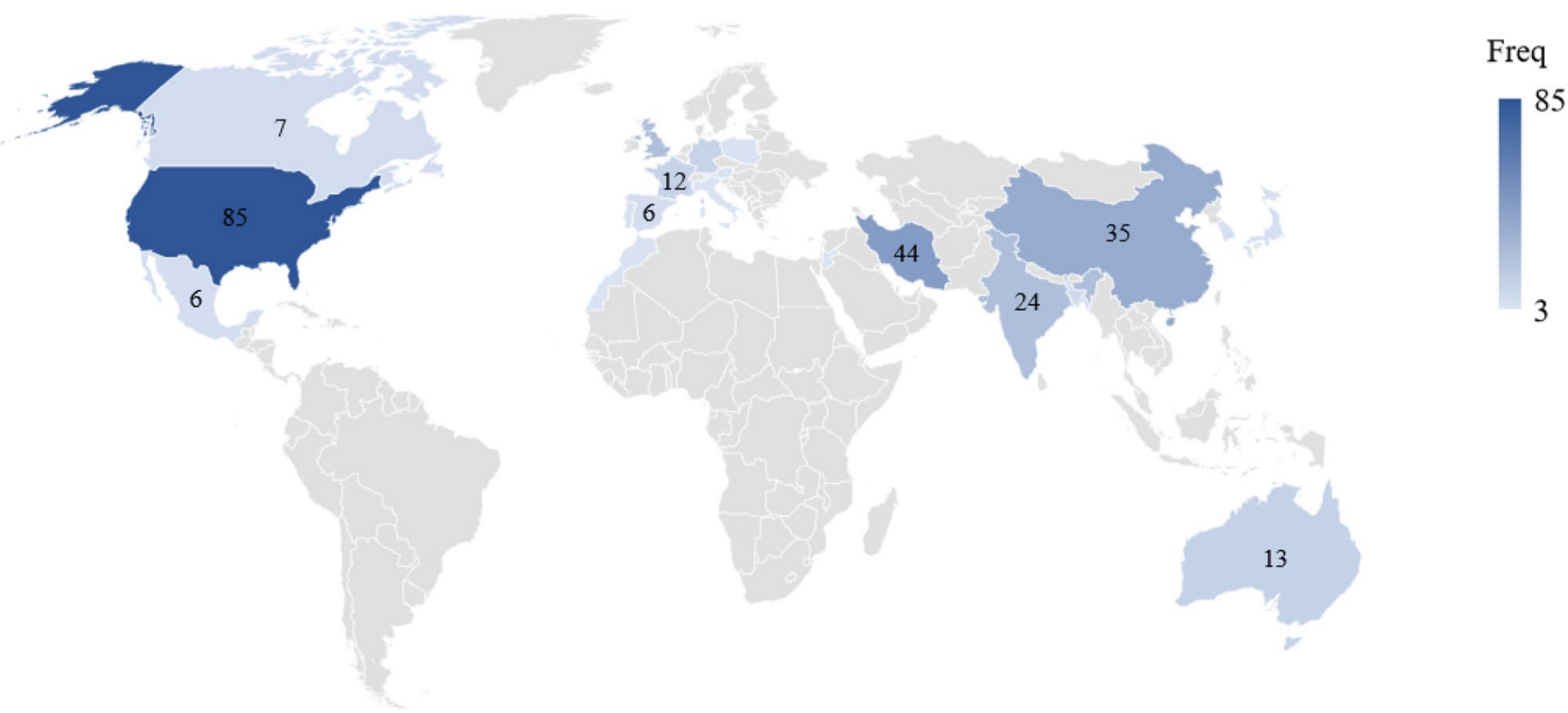

Fig. 3 Country-wise number of articles published in AI and SCR

\section{Text analytics using structural topic modeling}

Topic modeling (TM) is used to scan and analyse texts from a set of documents, and it is considered an unsupervised machine learning technique. It is an essential technique that clusters word-groups automatically, learn itself by clustering similar expressions, and explore different themes that best describe the collected documents (Kuhn 2018; Sharma et al. 2021). The TM allows researchers to organize and study many documents. A probabilistic method to define the collected documents in terms of topics is called structural topic modeling (STM), which is a form of STM (Kuhn 2018). STM's goal is to enable a researcher to document metadata by finding topics and analysing their connection (Roberts et al. 2019).

Based on the frequency and similarity of words, text was analysed from the documents and thematic topics were generated using STM. It is a generative model of word counts, which implies that for each document the data generating method is defined. Then by using the data, it finds the most probable values for the parameters in the model (Roberts et al. 2019). The generative process of STM is specified in the following steps:

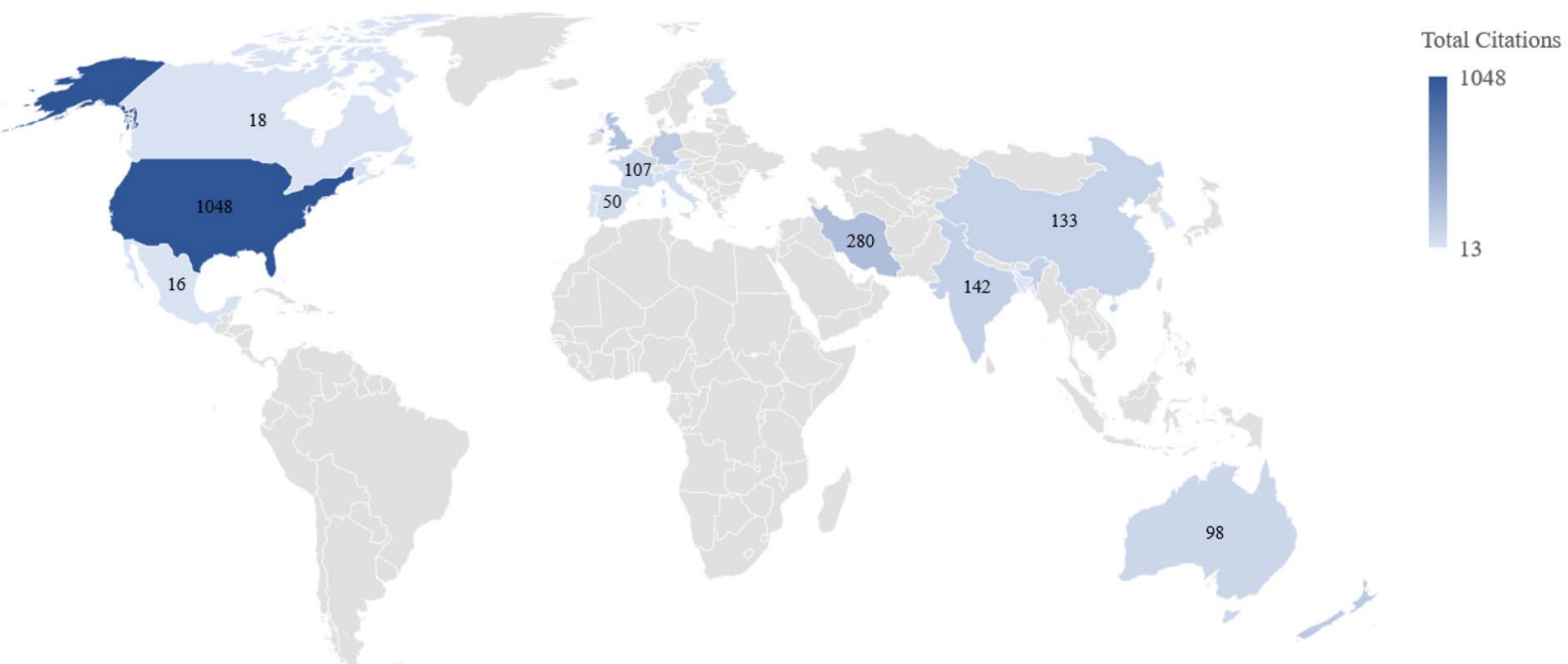

Fig. 4 Country-wise citations in the field of AI and SCR 
Table 2 Important journal publishing articles in the field of AI in SCR

\begin{tabular}{ll}
\hline Journals & Articles \\
\hline International Journal of Production Research & 16 \\
Computers and Industrial Engineering & 8 \\
International Journal of Production Economics & 5 \\
Annals of Operations Research & 4 \\
European Journal of Operational Research & 4 \\
IEEE Transactions on Engineering Management & 4 \\
Supply Chain Management & 4 \\
Expert Systems with Applications & 3 \\
Mathematical Problems in Engineering & 3 \\
International Journal of Information Management & 2 \\
\hline
\end{tabular}

Step 1: Analyse the topic parameter $\theta_{d}$ for each word in document $d$ by using the log-normal linear model from the vector of document covariates $X_{d}$.

$$
\overrightarrow{\theta_{d}} \mid X_{d} \Upsilon, \Sigma \sim \operatorname{LogisticNormal}\left(\mu=X_{d} \Upsilon, \Sigma\right)
$$

where, $X_{d}$ represents 1-by-P vector, $\Upsilon$ represents P-by$(K-1)$ matrix of coefficients, and $\Sigma$ represents a covariance matrix of $(K-1)$ - by- $(K-1)$.

Step 2: Generate the topic model $\beta$ that represents words of each topic ( $K$, by utilizing baseline distribution (m) of length V, the topic-specific deviation $K_{k, v}^{(t)}$ of topic $k$, the covariate group deviation $K_{y d, v}^{(c)}$ of topic $K$, and the interaction between each topic and group deviation $K_{y d, k, v}^{(i)}$

$\beta_{d, k, v}=\frac{\exp \left(m_{v}+K_{k, v}^{(t)}+K_{y d, v}^{(c)}+K_{y d, k, v}^{(i)}\right)}{\sum_{v} \exp \left(m_{v}+K_{k, v}^{(t)}+K_{y d, v}^{(c)}+K_{y d, k, v}^{(i)}\right)}$

Step 3: For every word in collected documents (n $\left.\in\left\{1,2,3, \ldots \ldots . . N_{d}\right\}\right):$

Table 3 Important authors publishing articles in the field of $\mathrm{AI}$ in SCR
Table 4 Important organization publishing articles in the field of AI in SCR

\begin{tabular}{ll}
\hline Affiliations & Articles \\
\hline Islamic Azad University & 11 \\
Berlin School of Economics and Law & 6 \\
Iran University of Science and Technology & 6 \\
University of Southern Mississippi & 6 \\
Indian Institute of Technology & 5 \\
North Carolina State University & 5 \\
Bangladesh University of Engineering and Technology & 4 \\
University of Huddersfield & 4 \\
University of Technology Sydney & 4 \\
Cracow University of Technology & 3 \\
\hline
\end{tabular}

Draw word topic assignment based on an unsupervised model that can be generated from the multinomial distribution:

$Z_{d, n} \mid \overrightarrow{\theta_{d}} \sim \operatorname{Multinomial}\left(\overrightarrow{\theta_{d}}\right)$

$W_{d, n} \mid Z_{d, n}, \beta_{d, k=Z_{d, n}} \overrightarrow{\theta_{d}} \sim \operatorname{Multinomial}\left(\beta_{d, k=Z_{d, n}}\right)$

To produce thematic topics from selected documents, the text from the article title, abstract, and keywords were combined to prepare a text corpus and used as the input in the STM approach. At first, text cleaning was done by removing commonly used words or stop. Secondly, special characters, numbers, equations, and non-English words were also eliminated to make text corpus compatible for STM approach.

A total of 162 articles were selected (Table 1). R-package is used to perform the STM approach by using the inbuilt STM library. The generated thematic topics from the STM approach are shown in Fig. 8.

Topic labels were generated from Fig. 8. Topic 1 labels "Risk associated with supply chain management" generated from the probabilistic distribution of most frequently used keywords like, 'supplier', 'risk', 'chain', 'network', 'disrupt', 'model', and 'cost'. Similarly, other topics are generated from respective keywords which are presented in Table 6.

Topic 1: Risk associated with supply chain management, Topic 2: Sustainable transportation and logistics, Topic 3: Resiliency in supply chain, Topic 4: Supplier risk management, Topic 5: Data-driven supply chain, Topic 6: Decision model in supply chain, Topic 7: Technology management in supply chain firms, Topic 8: Network design in supply chain, Topic 9: Machine learning in supply chain, Topic 10: Optimization algorithm in supply chain.

The highly frequent words under each generate topic are shown in Table 6. Two other metrics, Frex and Lift are also presented, where lift shows frequent words which have importance for only a particular topic and can be regarded 
Table 5 Top keywords in the field of AI in SCR

\begin{tabular}{llll}
\hline Words & Occurrences & Words & Occurrences \\
\hline Supply Chains & 80 & Optimization & 13 \\
Supply Chain Management & 42 & Supply-Chain Disruptions & 13 \\
Decision Making & 33 & Uncertainty Analysis & 13 \\
Risk Management & 25 & Stochastic Systems & 11 \\
Artificial Intelligence & 24 & Costs & 10 \\
Genetic Algorithms & 24 & Economic and Social Effects & 10 \\
Risk Assessment & 24 & Supplier Selection & 10 \\
Bayesian Networks & 23 & Supply Chain Network & 10 \\
Decision Support Systems & 17 & Forecasting & 9 \\
Manufacture & 13 & Integer Programming & 9 \\
\hline
\end{tabular}

as rare words. Frex, on the other hand, denotes frequent and exclusive words to a specific topic. After the topic's generation by STM approach, articles based on each topic were reviewed. The discussion for each topic has been provided in the next section. The world map of evolving research themes is shown in Fig. 9.

\section{Emerging research themes of Al and supply chain resiliency}

\subsection{Risks associated with supply chain management}

In this context, risk can be defined as the possibility of arising unexpected or unwanted negative repercussions from an activity or event (Rowe 1980), and manmade or natural disasters (Shahed et al. 2021). The risks associated with the supply chain can be defined as the disruption caused by exposure to an event or activity that affects the management of the supply chain network (Christopher and Lee 2004). In this modern and global environment, managing risks is gradually becoming challenging because of the uncertainties associated with demand and supply, outsourcing from global companies, and short life cycles of products (Ghadge et al. 2012). Also, the risks associated with poorly handled project management reflects in the entire supply chain because the project risks are not well communicated all through the supply chain (Thunberg et al. 2017). Similarly, Zuo et al. (2009) asserted that the availability of international sources is not beneficial anymore because of the lack of communication between project management and procurement teams and because of lack of management in the entire supply chain. On the other hand, global sourcing is often linked with complexities comparing to a simple internal supply chain or project, for instance, export regulations, taxes, import and export duties, exchange rate fluctuations, increased transportation costs, etc. (Tang and Musa 2011).

Shahed et al. (2021) referred to the supply chain risks experienced due to disruptions caused by natural disasters like an outbreak of coronavirus. Since November 2019, coronavirus (SARS-COV-2) has become a disruption risk and has destroyed the whole supply chain activities (Taqi
Fig. 5 Word Cloud for AI and SCR research work

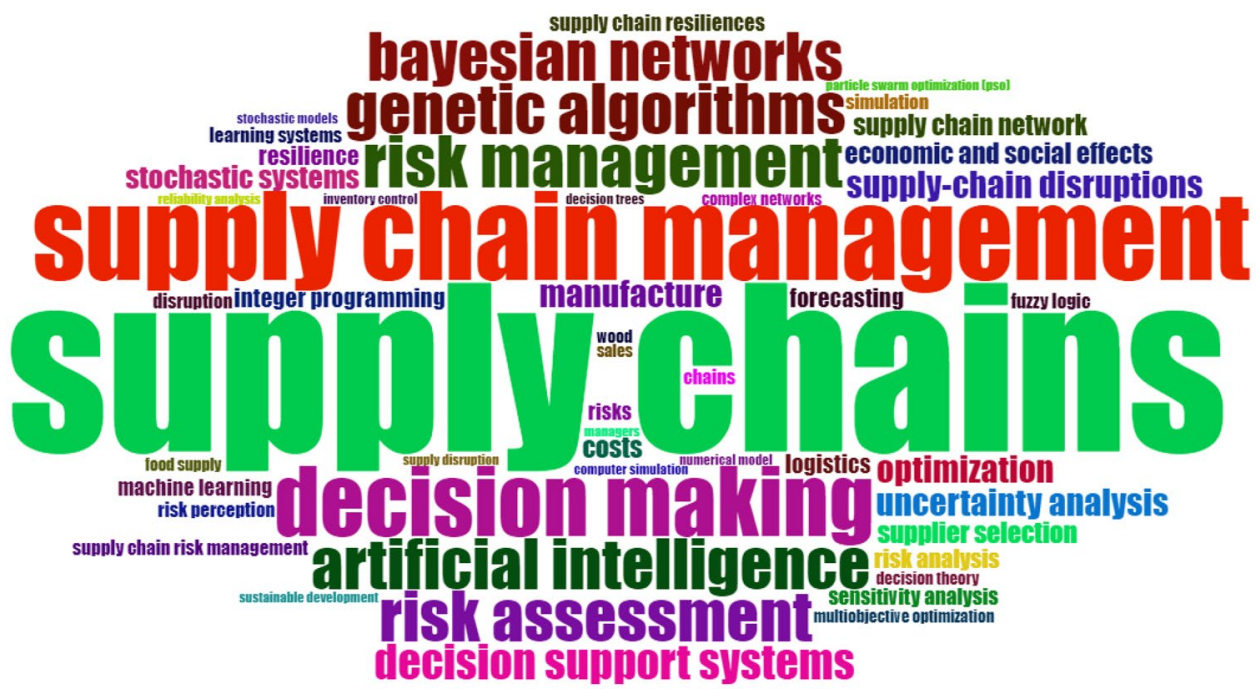




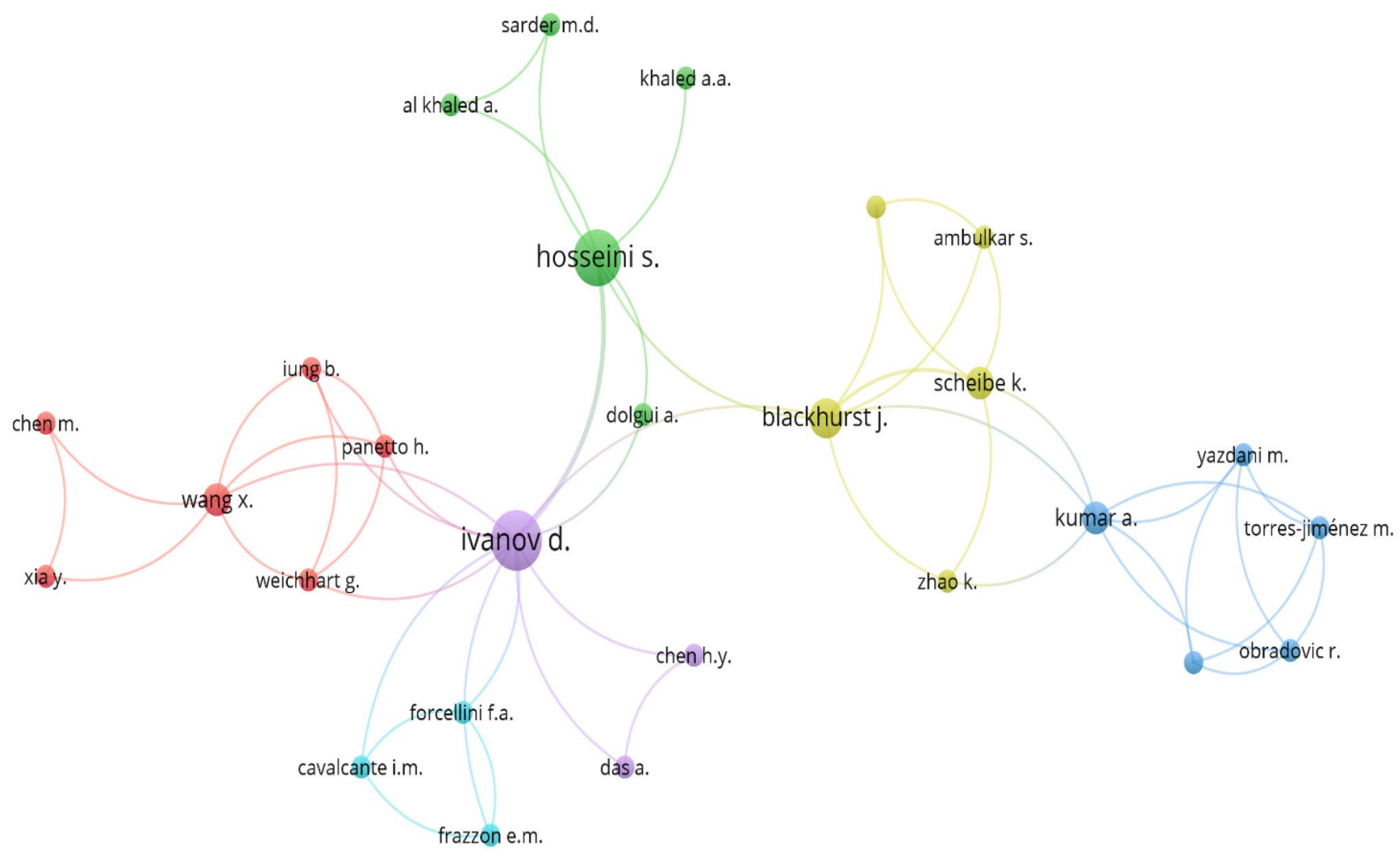

Fig. 6 Author collaboration for AI and SCR research work

et al. 2020) through restrained air transport facilities, unavailability of raw materials supply, border closure, and the entire shutting down of production activities (Chowdhury et al. 2020). The ongoing pandemic has significantly affected every type of supply chain, like, the food supply chain (Barman et al. 2021), medicine supply chain (Goodarzian et al. 2021a), commercial products supply chain (Paul and Chowdhury 2020), etc.

The pandemic created dual disruptions like a rapid increase in demand for high-demand products like hand sanitiser, toilet paper, etc., and a decrease in the supply of the raw material in supply chains (Koonin 2020). To reduce the negative impacts of the COVID-19 pandemic agile project management was proposed (Koch and Schermuly 2021). A production recovery model was established by using a mathematical modeling approach to overcome these disruptions in the supply chain of high-demand and essential products during the pandemic (Paul and Chowdhury 2020). To develop sustainable SCM, an operational excellence approach was applied through the role of big data analytics (Bag et al. 2020). Furthermore, 33 barriers were identified in innovations for sustainable SCM in the manufacturing industry of a developing country, and a framework to overcome these barriers was provided by using the best-worst method (Gupta et al. 2020). However, Fasan et al. (2021) reported that companies with green SCM practices experienced less negative abnormal stock returns during the pandemic. They suggested that green SCM is identified as an effective risk management tool. Thus, we proposed the following propositions:

Proposition 1: To develop a supply chain model using AI techniques to mitigate sudden risks and disruptions caused by the COVID-19 pandemic.

Proposition 2: To recommend applicability and benefits of emerging technology like AI, 3D printing solutions, blockchain, automation, etc., in solving real-time issues and creating a resilient supply chain post-COVID-19.

Proposition 3: To assess both strengths and weaknesses of AI-enabled technologies in project management and SCR post-COVID-19.

\subsection{Sustainable transportation and logistics}

The growth and development of an economy lead to a massive rise in transportation activities. In industrialized countries, transportation has become a crucial and 
Fig. 7 Country collaboration for AI and SCR research work

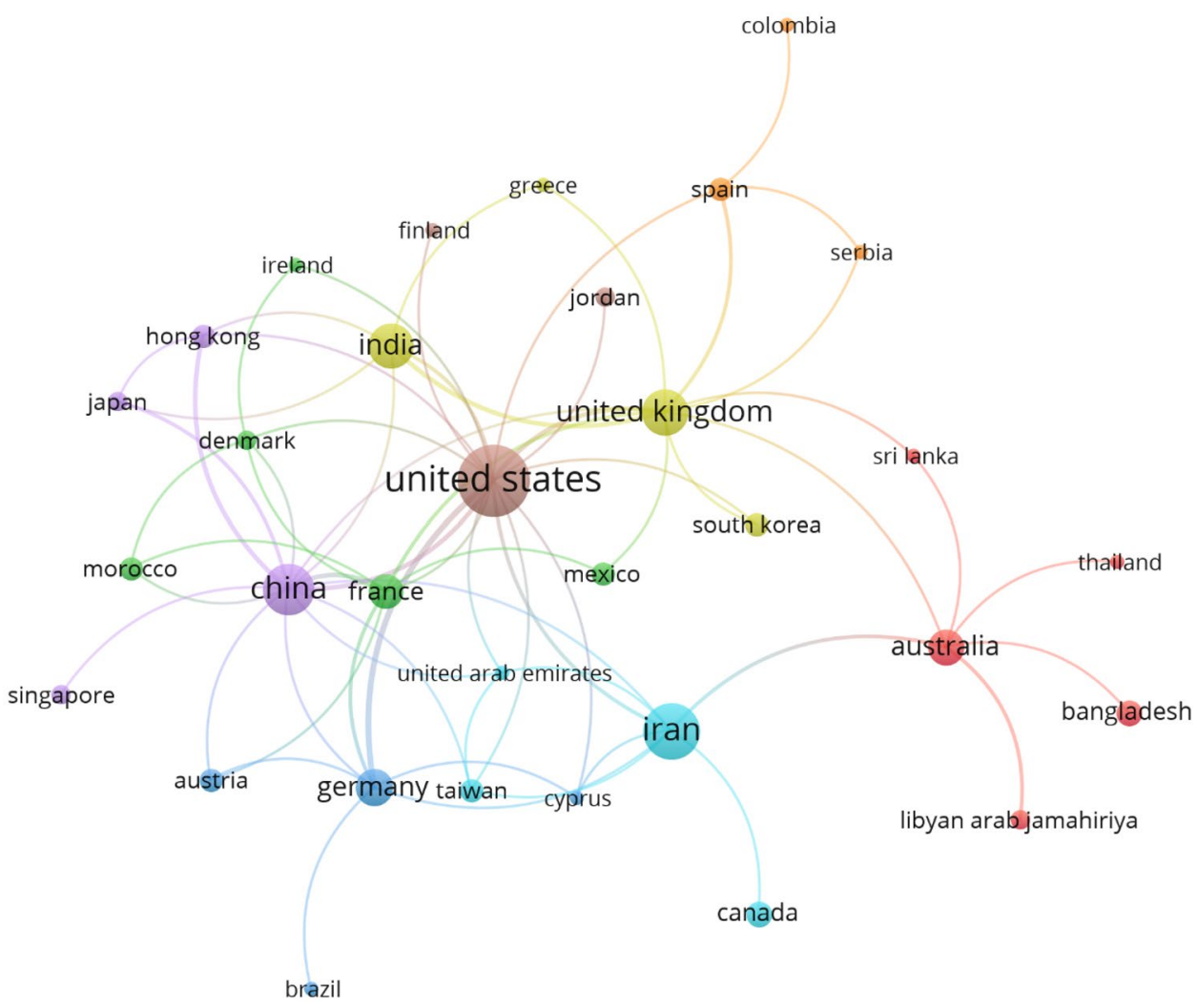

basic activity for social and economic development. As the gross domestic product grows, transportation activities certainly increase (Faulin et al. 2019). Transportation is linked to various adverse external effects like air and noise pollution, greenhouse gas emissions, accidents, etc. Also, it is a major contributor to human-induced climate change. It is reported that greenhouse gas emissions have grown globally at a faster rate in the transportation sector than in any other sector (Tchanche 2021). Logistical and transportation activities have numerous detrimental effects on the societal and natural environment which are necessary to be reduced. Therefore, sustainable development of transportation and logistics necessitate sustainable activities that reduce adverse environmental impacts and significantly bring social and economic benefits (Abbasi and Nilsson 2016).
Fig. 8 Generated topic labels from the STM approach

\section{Top Topics}

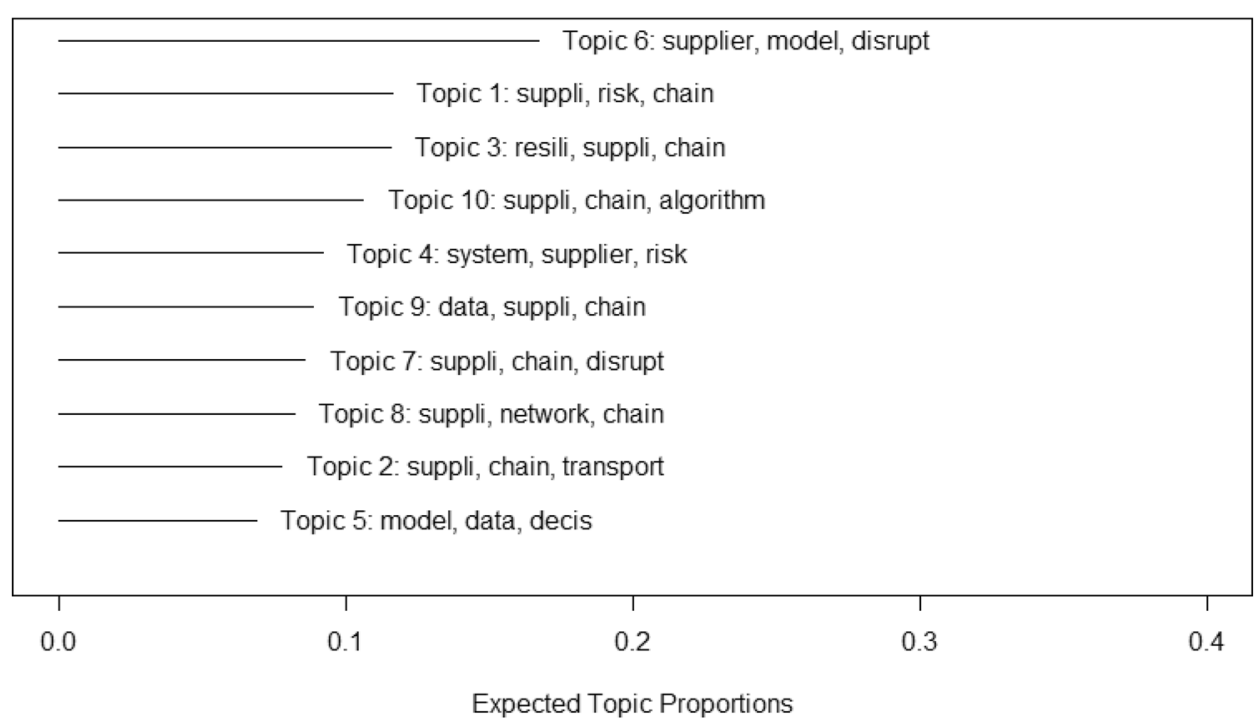




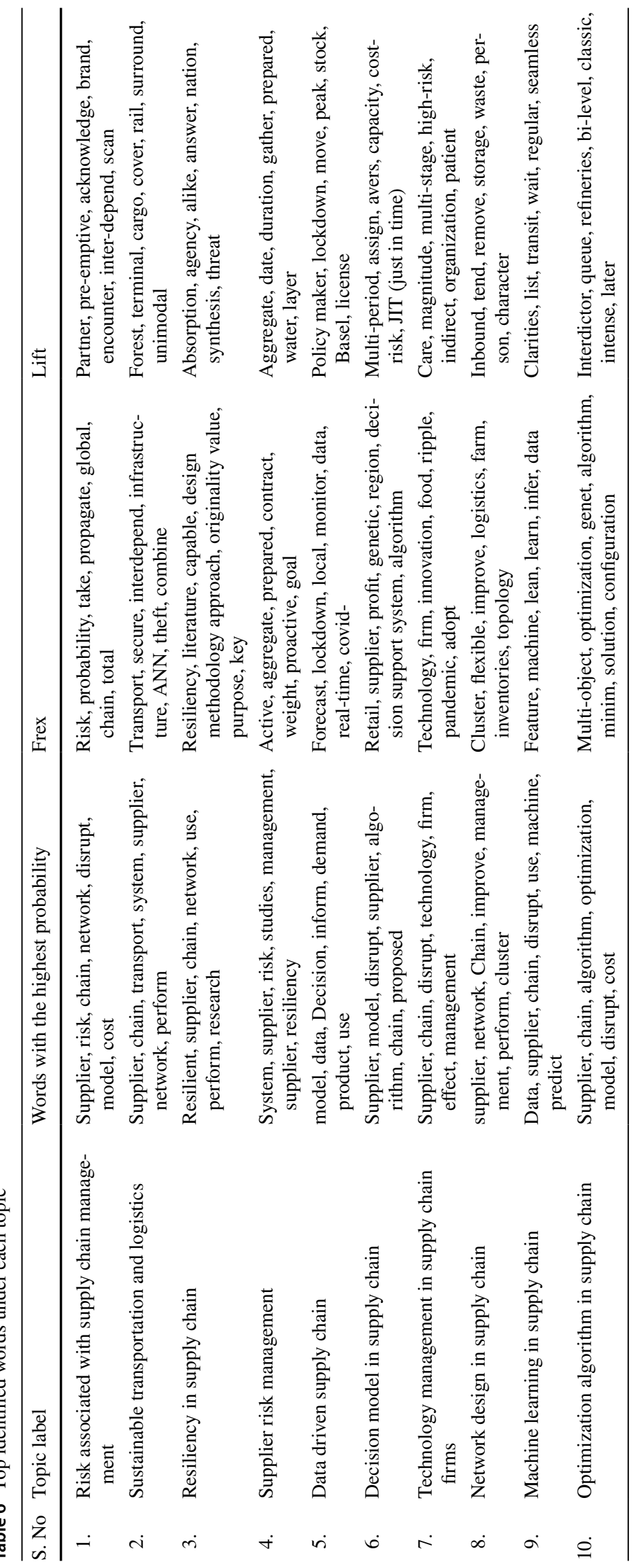




\begin{tabular}{|c|c|c|c|c|}
\hline 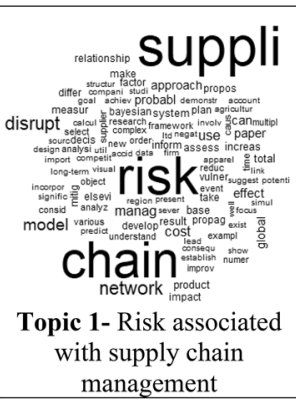 & 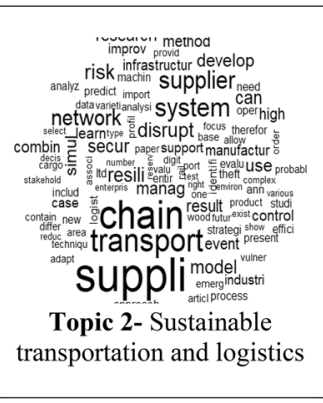 & 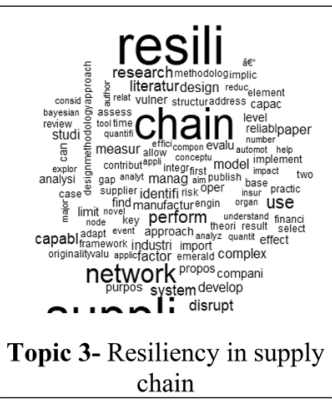 & 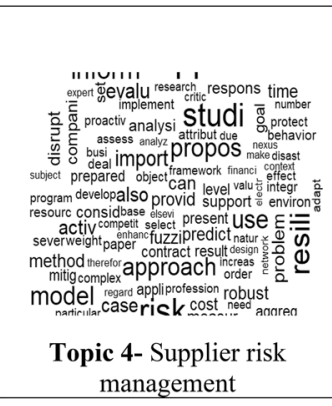 & 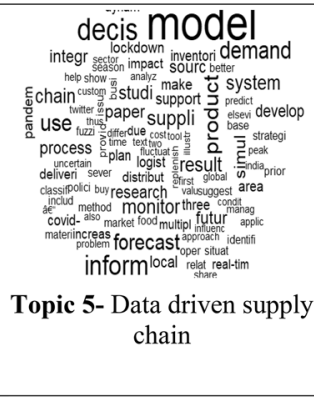 \\
\hline 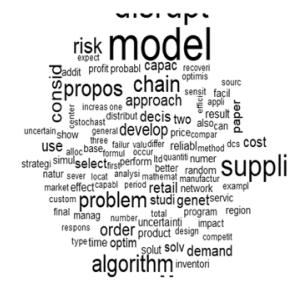 & 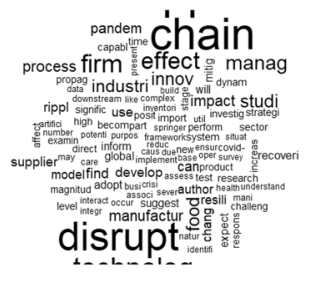 & 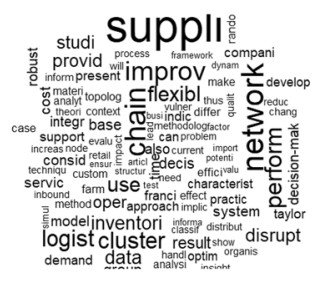 & 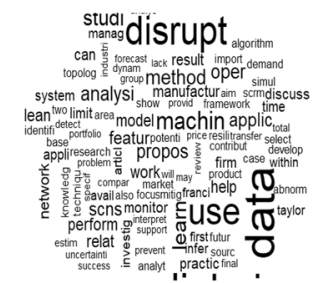 & 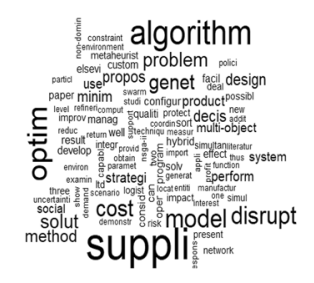 \\
\hline sion model & $\begin{array}{l}\text { Topic 7- Technology } \\
\text { management in supply chain } \\
\text { firms }\end{array}$ & $\begin{array}{l}\text { Network design in } \\
\text { ain }\end{array}$ & $\begin{array}{l}\text { pic 9- Machine learning in } \\
\text { pply chain }\end{array}$ & $\begin{array}{l}\text { Topic 10- O } \\
\text { algorithm in }\end{array}$ \\
\hline
\end{tabular}

Fig. 9 Word map of ten emerging research topics of AI and supply chain resiliency

The transport system comprises passenger mobility and freight transportation, which involves numerous additional processes like inventory management, storage management, returns and waste issues, project management, etc. These activities make it more challenging and concerning for further research regarding sustainable development (Gonzalez-Feliu 2018). To support decision making, quantitative methods are being applied in many fields such as logistics, transportation, SCM, and risk minimization (Render and Stair 2017). Pishvaee and Razmi (2012) proposed a fuzzy mathematical programming model which is used to develop an environmental supply chain during disruptions. An integrated approach was presented based on system dynamics simulation and an analytic network process to examine policies for sustainable transport (Sayyadi and Awasthi 2020). Neto et al. (2008) reviewed the main activities in logistic networks that affect cost efficiency and environmental performance. They highlighted the benefits of using multi-objective programming (MOP) to develop or design a sustainable network. Nonetheless, a hybrid multi-criteria method is used to examine economic, social, environmental and risk aspects, by employing fuzzy analytic hierarchy process (AHP) and fuzzy vlsekriterijumska optimizacija i kompromisno resenje (VIKOR) methods for creating sustainable supply chain and logistics (Wang et al. 2021). Thus, we proposed the following:

Proposition 4: To analyse the effectiveness of advanced technologies in reducing social, economic, and environmental impacts of transportation and logistics.
Proposition 5: The COVID-19 emergency implies the critical necessity of implementing sustainable practices in logistics and transportation.

Proposition 6: To develop an AI-based model to solve social and environmental issues in supply chains and link it with sustainable development.

Proposition 7: Future studies may evaluate the impact of different sustainable transport and logistics practices such as eco-design, net-zero carbon supply chain, research and development management, etc.

\subsection{Resiliency in supply chain}

Many failures or disruptions have been observed in the supply chain by which firms get affected because of the unexpected changes in consumer demand and partly due to the inability of new technological innovation adoption (Singh et al. 2019). Recent economic and business risks that occurred due to the outbreak of the COVID-19 pandemic have shifted the focus of the practitioners and researchers to develop a resilient supply chain network (Spieske and Birkel 2021). Although resilience is regarded as a broad concept, core concern involves measurement of the effectiveness and performance of the entire system which comprises production line, supply chain network, telecommunication network, etc. (Singh et al. 2019). In the entire project, even delay in some activities can disrupt the whole network and reduce project resilience. In this regard, the disruptions caused by the COVID-19 pandemic are probably the most severe in the last decade to the global supply chain (Araz 
et al. 2020). Previous literature gives evidence from various studies to explain the antecedents of SCR (Bode et al. 2011; Kim et al. 2015).

To efficiently managing disruptions in the supply chain in case of a pandemic, a decision support system based on the Fuzzy Inference System (FIS) is effective to manage the demand for healthcare supplies (Govindan et al. 2020). Considering the outbreak and the corresponding risks in the supply chain, a simulation model is proposed to manage global supply chain disruption and to predict the severe outcomes of COVID-19 impact on supply chain performance (Ivanov and Dolgui 2020). Kumar and Anbanandam (2020) offered an SAP-LAP framework to enhance the supply chain resilience and to initiate resilience-building processes. Furthermore, an agent-based model (ABM) was developed using simulation software providing recovery plans and several strategies to manage skyrocketing demand of essential items during pandemic (Rahman et al. 2021). Thus, we proposed the following propositions:

Proposition 8: Spply chain recovery model using innovative technology and big data analytics is required to overcome the SCR issues during an outbreak.

Proposition 9: The COVID-19 emergency has created a need for resilient strategies to reduce production and delivery complexities.

Proposition 10: To evaluate not only short-term recovery model for SCR but also long-term strategies to recover and regain strength post-pandemic by using AI efficiency.

Proposition 11: Future studies must integrate the role of project management in SCR post pandemic because only a limited number of studies exists concerning project management and SCR.

\subsection{Supplier risk management}

Supplier risk management considers the risks associated with the wrongdoing or misconduct of suppliers (Canzaniello et al. 2017). The supplier selection decision is regarded as one of the major issues in the context of project management (Sabbaghi 2020) and SCM faced by managers to retain competitiveness (Bai and Sarkis 2010). The risk associated with supplier selection can cause disruptions in entire project management and subsequently affect the supply chain. Also, the overall purchasing cost is influenced by the selection of the right supplier, which impact the overall cost of the final product (Pazhani et al. 2016).

Sun et al. (2012) proposed a quality risk management model and developed a P-chart solution model to mitigate quality risks in a supplier-assembler structure supply chain. The issue in the manufacturing supply chain was studied that comprises multiple suppliers and multiple uncertainties, and an integrated inventory management policy was formulated by using the stochastic dynamic programming approach to enable supplier risk management (Song et al. 2014). Wu et al. (2010) developed a fuzzy multi-objective programming model for supplier selection considering risk factors. Many studies related to supplier risk management have similarities with decision modeling work. A decision model was developed by applying a traditional supply risk management approach in consideration with qualitative and quantitative risk factors in the selection of suppliers and evaluating other strategies for risk mitigation (Yoon et al. 2018). In addition, a data mining approach was used for supplier risk management by ascertaining latent association among pre-qualification data of supplier and overall rating of the supplier (Jain et al. 2014). However, there are many techniques in AI like Bayesian networks, fuzzy logic, differential evolution, etc., that are not employed in this field of research of supplier risk management (Hamdi et al. 2018). In the field of supply chain risk management and supplier selection, Hamdi et al. (2018) conducted a literature review study and concluded that the research in this field is not considered enough in comparison to other fields of supply chain risk management. Thus, we proposed the following propositions:

Proposition 12: To develop an AI-enabled framework to mitigate the risks associated with supplier selection and project management.

Proposition 13: To develop supplier risk management model using AI techniques like fuzzy logic, Bayesian networks, artificial neural networks (ANNs), differential evolution, etc.

Proposition 14: There is a need for more scientific research in this field of SCM that offers optimum solutions using big data analytics.

Proposition 15: Future studies may incorporate green SCM practices in supplier selection management.

\subsection{Data-driven supply chain}

A data-driven supply chain is a supply chain that employs big data as the core of qualitative and quantitative techniques to improve supply chain competitiveness (Shamsuzzoha et al. 2020). Today, companies are investing greatly in projects based on information technology to optimize inventory levels, automate transactions, track supply and operations, and various supply chain decisions (Yu et al. 2018). This trend of the automated or data-driven supply chain provides significant prospects to enhance efficiency and reduce cost (Wu et al. 2016). The worldwide scope of the supply chain brings a large volume of collected data from its numerous processes. This big data is analysed and interpreted by the supply chain professionals to support decisions and to recommend new organizing techniques of the supply chain 
(Hazen et al. 2014). A big data strategy implementation in the project management and supply chain could bring potential improvements in effectiveness and efficiency through all project activities like demand forecasting, location monitoring, supply planning, product, and service acceptance, understanding supplier and customer behaviour, etc. (Kwon et al. 2014).

Over the next decade, tremendous changes are expected in the supply chain and logistics, such as technology influence on information or data flows, autonomous decision making, new cooperation models in value networks connections, big data analytics, etc. (Nitsche et al. 2021). Wanke et al. (2017) suggested that a good inventory allocation model manages various decisions regarding the logistic plan of inventories from sellers to consumers when there is insufficient stock to meet each consumer demand. A data-driven approach can be employed to ascertain factors enabling resilience in the supply chain and the importance of quality information sharing, and swift trust can be emphasized (Papadopoulos et al. 2017). Cavalcante et al. (2019) developed a data-driven hybrid technique to theorize the concepts of resilient supply chain performance. Furthermore, based on the information sharing and using hybrid industry 3.5 strategy, a material resource allocation, and management approach can also be developed in supply chains which can meet around 90 percent consumer material fulfilment rate (Kuo et al. 2021). Thus, we proposed the following propositions:

Proposition 16: A multi-product and multi-horizon approach using big data and AI should be developed to bring resiliency in the supply chain post-COVID-19.

Proposition 17: The COVID-19 emergency indicates a need for a data-driven forecast model that provides demand and supply surges during an outbreak and enables supply chain firms to monitor their operations accordingly.

Proposition 18: In a rapidly changing scenario, modification of existing strategies is required to overcome supply chain disruptions during the pandemic.

\subsection{Decision model in supply chain}

At each level in the supply chain, effective decision-making plays a vital role in the reduction of inventory cost, fulfil consumer demands, expand market share, and enhancing customer service level (Singh et al. 2019). Similarly, a significant impact is posed by decision-making on the resilient abilities of the company. For this purpose, developing a decision support system by supply chain automation is among the several approaches of optimum decision making (Wang et al. 2013). Riahi et al. (2014) established a mathematical decision-making model to evaluate the security score of the container by using analytical hierarchy and the Bayesian network process. This model was used to reduce the risks in the logistic process, to analyse security-based disruptions, and provide an acceptable security level. To quantify several resilient strategies for risk mitigation, a decision support model can be developed with the combination of layered analytic network process (ANP) and grey theory as in the casestudy of electronics producing companies conducted by Rajesh (2020).

An ontology-based decision support system is recommended to strengthen resilience in the supply chain during a disruption by using PSO-DE as an optimization technique (Singh et al. 2019). By contemplating the awareness of online consumers regarding carbon emissions, a low-carbon decision-making model can be established based on online shops and sellers (Wu et al. 2021). Pamucar et al. (2020) proposed a fuzzy neutrosophic approach for decision-making for the selection and evaluation of suppliers. Furthermore, the impact of COVID-19 disruptions on supply chain decisions must be examined and a stochastic optimization model may be proposed for sharing and allocating a critical resource during a pandemic (Mehrotra et al. 2020). Thus, we proposed the following propositions:

Proposition 19: To investigate the enablers of a sustainable supply chain and propose an AI-based decision model to overcome the challenges that occur due to pandemics. Proposition 20: To develop the model using fuzzy MICMAC and fuzzy TISM and based on experts' recommendations without biasness.

\subsection{Technology management in supply chain firms}

Technology management is defined widely as "a process, which includes planning, directing, control and coordination of the development and implementation of technological capabilities to shape and accomplish the strategic and operational objectives of an organization" (Cetindamar et al. 2009). It is crucial to evaluate the impact of information technology on today's organization as it has become a fundamental aspect of SCM. An efficient and successful SCM relies on the management of the quality and technology within the technical and social system of the supply chain. These technical and social systems are established on the connections of several factors that lie within quality and technology management (Kuei et al. 2001). In transportation and logistics, technological development is bringing efficiency and improvements. The activities related to technological innovation can help supply chain firms to increase productivity, reduce risks and costs (Fu et al. 2021).

Lee et al. (2018) stated that technology innovation is an important factor for the sustainable growth of the company and in recent years, many companies are shifting their 
attention to technology management to achieve competitive advantage. For this purpose, they proposed an ensemble model to support technological integration for achieving companies' sustainable growth. On the other hand, for freight transportation, sustainable technologies were evaluated by using spherical fuzzy AHP and TOPSIS approach (Jaller and Otay 2020). The impact of technology management was investigated on the sustainable performance of the company through empirical research (Tasleem et al. 2019). Furthermore, the adoption barriers of blockchain technology were investigated for accomplishing a sustainable supply chain (Kouhizadeh et al. 2021). A two-stage strategic framework was established by Kuei et al. (2002) that provide strategies for technology management and supply chain quality enhancement. However, by thoroughly reviewing the literature it is found that there is a dearth of literature regarding supply chain firms and technology management models. Thus, we proposed the following propositions:

Proposition 21: To develop a framework using AI techniques to facilitate recovery strategies and sustainable operations in supply chains covering various sectors.

Proposition 22: To identify the drivers and barriers in technology management to create a sustainable and resilient supply chain.

\subsection{Network design in supply chain}

Network design in the supply chain is sometimes regarded as strategic supply chain planning which is a part of the SCM planning process. It governs the physical structure and infrastructure of the supply chain (Govindan et al. 2017). A firm's or system's capability to revert to its initial condition or rather to a more advantageous state after disruption is called resilience (Tang 2006). This ability in SCM is directly influenced by the network design, which is one of the most important parts of any project. However, a resilient network of the supply chain must operate effectively in both situations, either normally or during disruptions (Hasani et al. 2021). In the area of creating reliable supply chain network design models, many studies undertake failure probability as a pre-specified constraint for transportation or facility under disruptions (Hatefi et al. 2015). As far as disruptions caused by the COVID-19 pandemic are concerned, there is a critical need for a sustainable network design to overcome the present and upcoming challenges. According to Majumdar et al. (2020), during COVID-19 the growing concern to fulfil environmental and social requirements are pushing pharmacies/hospitals to contemplate the influence of sustainable supply chain network design on the environment and society. Though, there is a dearth of good mathematical models in this area of research (Goodarzian et al. 2021a).
Fattahi (2020) proposed a data-driven approach for the development of socially accountable supply chain networks under disruptions. A multi-objective optimization model was proposed to enable a sustainable supply chain network design under uncertainty by using strength Pareto evolutionary algorithm 2 (SPEA2) (Hasani et al. 2021). Zahedi et al. (2021) developed a relief supply chain network using the internet of things (IoT) to analyse several suspected cases during the pandemic. Mehar approach was suggested to solve the distance problem in the supply chain network, by using the lexicographic method to compare interval-valued Pythagorean fuzzy numbers (Bhatia et al. 2021). To establish a sustainable supply chain network Lahri et al. (2021) proposed a multi-objective possibilistic integer linear programming model using the integrated possibilistic programming, TOPSIS, BWM, and Epsilon $(\varepsilon)$ constraint method. Thus, we proposed the following propositions:

Proposition 23: Use of AI technique to minimize the risks for two-echelon resilient supply chain network design.

Proposition 24: To explore the role of industry 4.0 techniques in creating resilient supply chain network design. Proposition 25: To ascertain the effectiveness of AI applications in managing and recovering the supply chain from sudden disruptions like a pandemic.

\subsection{Machine learning in supply chain}

Machine learning is the tool that facilitates the reduction and elimination of the negative impact of data interpretation because it does not entail direct human involvement. It responds quickly to the demands of the industries by incorporating the large data set as the input into the system (Tjahjono et al. 2017). To survive the increasing competition, automation is growing rapidly in industrial entities where they use software-enabled systems as the communication medium (Siderska and Jadaan 2018). Machine learning is considered one of the best tools in the present scenario as it focuses on resource optimization in the supply chain (Nagar et al. 2021). Machine learning helps project managers to easily organize thousands of tasks while managing all resources and project. Sindhwani et al. (2019) reported that the data input and analysis in the traditional supply chain and project management were performed manually which constraints the effective handling of the issues throughout the supply chain. In addition, data analysis was not adequate in some cases which led to interpretation of negative influence of the reliability of business operations (Kersten et al. 2019).

Therefore, to mitigate these risks and adverse effects of disruptions in the supply chain, the application of machine learning has received growing attention in recent years (Baryannis et al. 2019b). To measure the risk behaviour Bayesian network theory was used to examine the 
multi-echelon network-facing real-time disruptions in the supply chain (Ojha et al. 2018). A hybrid technique that combines machine learning and simulation was developed and used to examine its applicability in decision-making support in SCP and resilient supplier selection (Cavalcante et al. 2019). Furthermore, Wichmann et al. (2020) discussed automated supply chain mapping to maintain supply chain structural visibility by using deep learning which facilitated automatic extraction of the supplier-buyer relation from natural language text. It enabled firms to validate existing supply chain maps, generate fundamental supply chain maps automatically, and enhance existing maps with further information of the suppliers. Thus, we proposed the following propositions:

Proposition 26: To explore other machine learning techniques and a more feature-rich dataset like deep learning and neural networks etc. and to examine its applicability and effectiveness.

Proposition 27: To identify the barriers in SCR and big data solutions using machine learning techniques by applying cause-effect relationships.

\subsection{Optimization algorithm in supply chain}

An optimization algorithm is a method to compare various solutions until an effective and optimum solution for a problem is generated (Sadeghi et al. 2021). In this age of digitalization and AI, regulating the supply chain through emerging technologies becomes an integral part of the firms to generate sustainable output. Optimization algorithm provides an effective system to manage and control large projects. The scope of big data in many fields is massive but there is a shortage of literature in designing and formulating optimization models using big data analytics for the problems related to the supply chain (Goodarzian et al. 2021b). A two-stage supply chain distribution optimization model was proposed using a modified particle swarm optimization (MPSO) to solve inventory control and integrated location problems (Mousavi et al. 2017). Fathi et al. (2021) developed an optimization model for location-inventory supply chain by employing a two-phase approach based on stochastic optimization and queuing theory, and a hybrid genetic algorithm was created to mathematically tract the problem. Nevertheless, to solve the substantial problems in the supply chain using big data characteristics two hybrid meta-heuristic algorithms were proposed (Goodarzian et al. 2021b). Thus, we proposed the following propositions:

Proposition 28: The AI algorithms adoption to perform real-time data analysis in solving the resiliency issues in the supply chain during disruptions.
Proposition 29: To explore the strength of AI techniques and optimization algorithms in finding solutions to create sustainable multi-stage or multi-channel supply chain networks.

\section{Discussion and proposed research model}

The current study was conducted to analyse the impact of AI techniques in creating a resilient supply chain. The study has also taken into consideration the disruptions caused by the COVID-19 pandemic on the global SCM. The STM approach and a systemic literature review was adopted to explore the research on SCR and AI. The generated thematic topics, such as Risk associated with SCM, sustainable transportation, and logistics, resiliency in supply chain, supplier risk management, data-driven supply chain, decision model in supply chain, technology management in supply chain firms, network design in supply chain, machine learning in supply chain, optimization algorithm in supply chain have been identified. A significant contribution has been observed in respect to SCR and the application of AI. It was also reported that industry 4.0 technologies can facilitate risk mitigation ability to the firms to continue their operations during disruptions (Zhang et al. 2020). Shih (2020) supported this condition of current pandemic, where the unavailability of human labour is the most critical issue which potentially harms the operations of the supply chain. Subsequently, many researchers suggested that technologies of industry 4.0 such as AI, the IoT, and big data analytics, can help in building resilience in SCM (Dolgui and Ivanov 2020; Birkel and Hartmann 2020; Nayal et al. 2021).

The outbreak of the novel coronavirus (COVID-19) has uncovered the vulnerability of the supply chains at the beginning of the year 2020 (Govindan et al. 2020), although supply chains are under extreme pressure before this pandemic as well (Lechler et al. 2019). However, the disruptions necessitate resilience in a single supply chain only, but the systemic threats and pandemics disturb an entire supply chain that involves multiple value and supply chains only in a short time (Golan et al. 2020). The pandemic and lockdown in a country lead to logistic disruptions along with a shortage of labour force which eventually caused supply-side shocks to the supply chain. Furthermore, it brings an unexpected surge in the demand-side of the food supply chain because of hoarding behaviour and panic buying among consumers (Hobbs 2020). Hence, the logistic system becomes vulnerable in managing sudden disruptions and recovering the supply chain (Choi 2020) which brings forth the need for a stronger, more innovative and resilient supply chain. The literature recognizes that $\mathrm{AI}$ is considered a pathbreaking analytics tool to improve the performance of the supply chain (Grover et al. 2020). Several studies were conducted to analyse AI effectiveness in handling the supply chain 
disruption due to COVID-19 (Ivanov and Dolgui 2020; Nayal et al. 2021; Belhadi et al. 2021a).

Nayal et al. (2021) evaluated the challenges of employing machine learning and $\mathrm{AI}$ in the agriculture supply chain to reduce the impacts of COVID-19 by using a hybrid approach of Delphi ISM-Fuzzy MICMAC-ANP. They reported that data privacy and security are the biggest challenges in the implementation of machine learning and AI in the supply chain, although these technological applications turned out to be a powerful enabler to accurately predict and minimize uncertainties. The IoT is a robust tool for SCR as it enables items to track and determine crucial metrics along the entire supply chain (Kara et al. 2020). In another study, the short-term and long-term strategies were adopted, and the SCR model was developed by using sequential mixed-method for resilience evaluation, Financial Impact (FI) analysis, and integrating Time-to-Recovery (TTR). The results of the study supported the advanced use of industry 4.0 technologies in mitigating the risks related to the pandemic, also big data analytics play a crucial role in supply chain activities by providing real-time information to reduce disruptions (Belhadi et al. 2021b). Moreover, it is recommended that at the retail store level, companies should implement a contactless payment system to ensure safety measures (Mollenkopf et al. 2020). Similarly, easing capital flow was proposed to deal with the scarcity of capital for digitalization and restructuring the supply chain during or post COVID-19 (Deaton and Deaton 2020).
Improving technological capability in supply chains is crucial to overcome the disruptions caused by the pandemic. Therefore, requirements and acceptance of mobile services have grown significantly as customers prefer to receive products and services at their doorstep during COVID-19 (Choi 2020). For this purpose, it is suggested that companies should use online sales, digitalization, mobile services, and information technology to observe the supply chain and mitigate associated risks. In this regard, several technologies like, AI, 3-D printing, Big data analytics, cloud computing, and the IoT are recommended (Chowdhury et al. 2021). Also, to predict supply chain disruptions, adding agility to the data is suggested (Brintrup et al. 2020). A future research framework is proposed in Fig. 10.

The proposed research framework comprises ten emerging research themes of SCR in the first stage. The second stage involves several AI techniques that can be incorporated to achieve resiliency in the supply chain. In the last stage, the benefits of deploying AI techniques into SCM are presented. These benefits can be achieved during or post-pandemic to overcome disruptions.

\subsection{Implications}

The present study was conducted using bibliometric analysis and STM to examine the previous literature on AI in SCR. Based on STM-generated topics, a systematic literature review is carried out. This study contributes to the

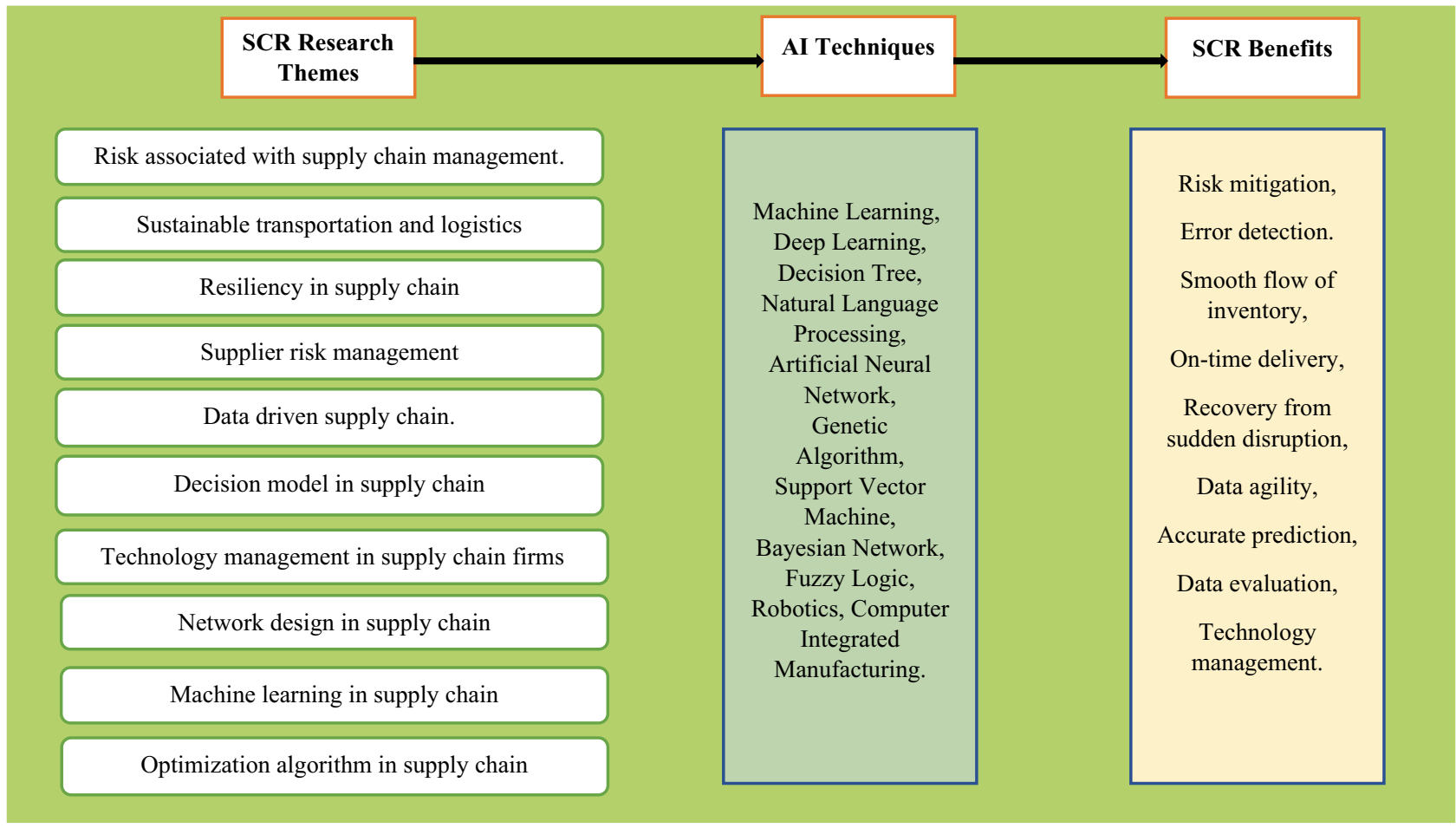

Fig. 10 A proposed research framework for AI in SCR 
literature by providing a review of existing studies in the field of AI, project management, supply chain, and SCR. The current study provides a review of the studies conducted before and during the COVID-19 pandemic related to SCR. It adds to the literature by providing a systematic literature review along with the application of bibliometric technique and network analysis to identify the most influential works in this field of study.

The outcome developed from the previous studies will help managers to utilize AI and industry 4.0 technique to achieve resilience in the supply chain during or postpandemic. This study will also help firms and practitioners by providing future research propositions. The implementation of AI techniques will enable firms and managers to mitigate sudden disruptions caused by any virus outbreak and to recover the supply chain instantly. The technological innovations and AI applications will help in creating a resilient supply chain and further facilitate risk mitigation, supplier selection, decision modeling, technology management, network design, data-driven and optimization algorithm in the supply chain.

\section{Conclusions}

The widespread transmission of the novel COVID-19 has developed grave uncertainties in the global supply chain. The effects of the pandemic have disrupted the entire supply chain mostly in every sector. In this regard, scholars and practitioners have shifted their focus to create a more sustainable and resilient supply chain. For this purpose, AIbased technological development has provided tools and techniques to implement in supply operations. The current study focuses on research work conducted in the field of AI in SCR. The various topics were identified, namely Risk associated with SCM, sustainable transportation and logistics, resiliency in supply chain, supplier risk management, data-driven supply chain, decision model in supply chain, technology management in supply chain firms, network design in the scs, machine learning in supply chain, optimization algorithm in SCs. Bibliometric analysis and STM were conducted to comprehend the research trends in AI and SCR. This research will provide a deeper and better insight into the implication of AI in SCR and it will help the SCM to mitigate the associated risks. An attempt is made to include most of the previous works related to AI in SCR based on the identified themes. The study is limited to only journal articles and does not include other papers such as conference papers, field reports, company reports, book chapters, etc. The bibliometric analysis will enable a researcher to classify the growth pattern and the amount of the previous literature available on AI in SCR. Consequently, we recommend future studies on the implication of AI and mitigating barriers in
SCR. It is also recommended to analyse the detrimental impact of AI on SCR, and to provide evidence regarding the weakness and challenges of AI-enabled technologies in the context of SCR.

\section{References}

Abbasi M, Nilsson F (2016) Developing environmentally sustainable logistics: Exploring themes and challenges from a logistics service providers' perspective. Transp Res Part d: Transp Environ 46:273-283

Agrawal R, Wankhede VA, Kumar A, Upadhyay A, Garza-Reyes JA (2021) Nexus of circular economy and sustainable business performance in the era of digitalization. Int $\mathrm{J}$ Prod Perform Manag Vol. ahead-of-print No. ahead-of-print. https://doi.org/ 10.1108/IJPPM-12-2020-0676

Araz OM, Choi TM, Olson D, Salman FS (2020) Data analytics for operational risk management. Decis Sci 51(6):1316-1319

Bag S, Wood LC, Xu L, Dhamija P, Kayikci Y (2020) Big data analytics as an operational excellence approach to enhance sustainable supply chain performance. Resour Conserv Recycl 153:104559

Bai C, Sarkis J (2010) Integrating sustainability into supplier selection with grey system and rough set methodologies. Int J Prod Econ 124(1):252-264

Barman A, Das R, De PK (2021) Impact of COVID-19 in food supply chain: Disruptions and recovery strategy. Current Research in Behavioral Sciences 2:100017

Baryannis G, Dani S, Antoniou G (2019a) Predicting supply chain risks using machine learning: The trade-off between performance and interpretability. Futur Gener Comput Syst 101:993-1004

Baryannis G, Validi S, Dani S, Antoniou G (2019b) Supply chain risk management and artificial intelligence: state of the art and future research directions. Int J Prod Res 57(7):2179-2202

Belhadi A, Kamble S, Jabbour CJC, Gunasekaran A, Ndubisi NO, Venkatesh M (2021a) Manufacturing and service supply chain resilience to the COVID-19 outbreak: Lessons learned from the automobile and airline industries. Technol Forecast Soc Chang 163:120447

Belhadi A, Mani V, Kamble SS, Khan SAR, Verma S (2021b) Artificial intelligence-driven innovation for enhancing supply chain resilience and performance under the effect of supply chain dynamism: an empirical investigation. Ann Oper Res. https://doi.org/ 10.1007/s10479-021-03956-X

Bhatia TK, Kumar A, Appadoo SS, Gajpal Y, Sharma MK (2021) Mehar Approach for Finding Shortest Path in Supply Chain Network. Sustainability 13(7):4016

Birkel HS, Hartmann E (2020) Internet of Things-the future of managing supply chain risks. Supply Chain Manag 25(5):535-548

Bode C, Wagner SM, Petersen KJ, Ellram LM (2011) Understanding responses to supply chain disruptions: Insights from information processing and resource dependence perspectives. Acad Manag J 54(4):833-856

Braglia M, Frosolini M (2014) An integrated approach to implement project management information systems within the extended enterprise. Int J Project Manage 32(1):18-29

Brintrup A, Pak J, Ratiney D, Pearce T, Wichmann P, Woodall P, McFarlane D (2020) Supply chain data analytics for predicting supplier disruptions: a case study in complex asset manufacturing. Int J Prod Res 58(11):3330-3341

Bushuyev S, Bushuiev D, Bushuieva V (2020) Project management during Infodemic of the COVID-19 Pandemic. Innovative Technologies and Scientific Solutions for Industries 2(12):13-21 
Canzaniello A, Hartmann E, Fifka MS (2017) Intra-industry strategic alliances for managing sustainability-related supplier risks: Motivation and outcome. Int J Phys Distrib Logist Manag 47(5):387-409

Cavalcante IM, Frazzon EM, Forcellini FA, Ivanov D (2019) A supervised machine learning approach to data-driven simulation of resilient supplier selection in digital manufacturing. Int J Inf Manage 49:86-97

Cetindamar D, Phaal R, Probert D (2009) Understanding technology management as a dynamic capability: A framework for technology management activities. Technovation 29(4):237-246

Choi TM (2020) Innovative "bring-service-near-your-home" operations under Corona-virus (COVID-19/SARS-CoV-2) outbreak: Can logistics become the messiah? Transport Res E-Log 140:101961

Chowdhury MT, Sarkar A, Paul SK, Moktadir MA (2020) A case study on strategies to deal with the impacts of COVID-19 pandemic in the food and beverage industry. Oper Manag Res. https://doi.org/ 10.1007/s12063-020-00166-9

Chowdhury P, Paul SK, Kaisar S, Moktadir MA (2021) COVID-19 pandemic related supply chain studies: A systematic review. Transport Res E-Log 148:102271

Christopher M, Lee H (2004) Mitigating supply chain risk through improved confidence. Int $\mathbf{J}$ Phys Distrib Logist Manag 34(5):388-396

Deaton BJ, Deaton BJ (2020) Food security and Canada's agricultural system challenged by COVID-19. Can J Agric Econ 68(2):143-149

Dolgui A, Ivanov D (2020) Exploring supply chain structural dynamics: New disruptive technologies and disruption risks. Int J Prod Econ 229:107886

Donthu N, Kumar S, Mukherjee D, Pandey N, Lim WM (2021) How to conduct a bibliometric analysis: An overview and guidelines. J Bus Res 133:285-296

Ellegaard O, Wallin JA (2015) The bibliometric analysis of scholarly production: How great is the impact? Scientometrics 105(3):1809-1831

Fasan M, Soerger Zaro E, Soerger Zaro C, Porco B, Tiscini R (2021) An empirical analysis: Did green supply chain management alleviate the effects of COVID-19? Bus Strateg Environ 30(5):27022712. https://doi.org/10.1002/bse.2772

Fathi M, Khakifirooz M, Diabat A, Chen H (2021) An integrated queuing-stochastic optimization hybrid Genetic Algorithm for a location-inventory supply chain network. Int J Prod Econ 237:108139. https://doi.org/10.1016/j.ijpe.2021.108139

Fattahi M (2020) A data-driven approach for supply chain network design under uncertainty with consideration of social concerns. Ann Oper Res 288:265-284

Faulin J, Grasman SE, Juan AA, Hirsch P (2019) Sustainable transportation: concepts and current practices. Sustainable Transportation and Smart Logistics. https://doi.org/10.1016/B978-0-12-8142424.00001-6

Fu H, Ke GY, Lian Z, Zhang L (2021) 3PL firm's equity financing for technology innovation in a platform supply chain. Trans Res E-Log 147:102239

Gaudenzi B, Christopher M (2016) Achieving supply chain 'Leagility'through a project management orientation. Int J Log Res Appl 19(1):3-18. https://doi.org/10.1080/13675567.2015.1073234

Ghadge A, Dani S, Kalawsky R (2012) Supply chain risk management: present and future scope. Int J Logist Manag 23(3):313-339

Golan MS, Jernegan LH, Linkov I (2020) Trends and applications of resilience analytics in supply chain modeling: systematic literature review in the context of the COVID-19 pandemic. Environ Syst Decis 40:222-243

Gonzalez-Feliu J (2018) Sustainability evaluation of green urban logistics systems: literature overview and proposed framework. Green Initiatives for Business Sustainability and Value Creation. https://doi.org/10.4018/978-1-5225-2662-9.ch005
Goodarzian F, Kumar V, Abraham A (2021a) Hybrid meta-heuristic algorithms for a supply chain network considering different carbon emission regulations using big data characteristics. Soft Comput 25(11):7527-7557. https://doi.org/10.1007/s00500-021-05711-7

Goodarzian F, Taleizadeh AA, Ghasemi P, Abraham A (2021b) An integrated sustainable medical supply chain network during COVID19. Eng Appl Artif Intell 100:104188

Govindan K, Fattahi M, Keyvanshokooh E (2017) Supply chain network design under uncertainty: A comprehensive review and future research directions. Eur J Oper Res 263(1):108-141

Govindan K, Mina H, Alavi B (2020) A decision support system for demand management in healthcare supply chains considering the epidemic outbreaks: A case study of coronavirus disease 2019 (COVID-19). Transport Res E-Log 138:101967

Grover P, Kar AK, Dwivedi YK (2020) Understanding artificial intelligence adoption in operations management: insights from the review of academic literature and social media discussions. Ann Oper Res. https://doi.org/10.1007/s10479-020-03683-9

Gupta H, Kusi-Sarpong S, Rezaei J (2020) Barriers and overcoming strategies to supply chain sustainability innovation. Resour Conserv Recycl 161:104819

Hamdi F, Ghorbel A, Masmoudi F, Dupont L (2018) Optimization of a supply portfolio in the context of supply chain risk management: literature review. J Intell Manuf 29(4):763-788

Hasani A, Mokhtari H, Fattahi M (2021) A multi-objective optimization approach for green and resilient supply chain network design: a real-life Case Study. J Clean Prod 278:123-199

Hatefi SM, Jolai F, Torabi SA, Tavakkoli-Moghaddam R (2015) A credibility-constrained programming for reliable forwardreverse logistics network design under uncertainty and facility disruptions. Int J Comput Integr Manuf 28(6):664-678

Haus-Reve S, Fitjar RD, Rodríguez-Pose A (2019) Does combining different types of collaboration always benefit firms? Collaboration, complementarity and product innovation in Norway. Res Policy 48(6): 1476-1486

Hazen BT, Boone CA, Ezell JD, Jones-Farmer LA (2014) Data quality for data science, predictive analytics, and big data in supply chain management: An introduction to the problem and suggestions for research and applications. Int J Prod Econ 154:72-80

Hobbs JE (2020) Food supply chains during the COVID-19 pandemic. Can J Agric Econ 68(2):171-176

Ivanov D (2020) Predicting the impacts of epidemic outbreaks on global supply chains: A simulation-based analysis on the coronavirus outbreak (COVID-19/SARS-CoV-2) case. Transport Res E-Log 136:101-922

Ivanov D, Dolgui A (2020) A digital supply chain twin for managing the disruption risks and resilience in the era of Industry 4.0. Prod Plan Control 32(9):1-14

Ivanov D, Dolgui A, Sokolov B (2019) The impact of digital technology and Industry 4.0 on the ripple effect and supply chain risk analytics. Int J Prod Res 57(3):829-846

Jain R, Singh AR, Yadav HC, Mishra PK (2014) Using data mining synergies for evaluating criteria at pre-qualification stage of supplier selection. J Intell Manuf 25(1):165-175

Jaller M, Otay I (2020) Evaluating Sustainable Vehicle Technologies for Freight Transportation Using Spherical Fuzzy AHP and TOPSIS. In International Conference on Intelligent and Fuzzy Systems. Springer, Cham. 1197, 118-126

Kara ME, Firat SÜO, Ghadge A (2020) A data mining-based framework for supply chain risk management. Comput Ind Eng 139:105570

Katsaliaki K, Galetsi P, Kumar S (2021) Supply chain disruptions and resilience: a major review and future research agenda. Ann Oper Res 1-38

Kersten W, Blecker T, Ringle CM (2019) Artificial intelligence and digital transformation in supply chain management: innovative approaches 
for supply chains. Berlin: epubli GmbH. https://doi.org/10.15480/ 882.2460

Kim Y, Chen YS, Linderman K (2015) Supply network disruption and resilience: A network structural perspective. J Oper Manag 33:43-59

Koch J, Schermuly CC (2021) Managing the Crisis: How COVID-19 Demands Interact with Agile Project Management in Predicting Employee Exhaustion. Br J Manag. https://doi.org/10.1111/ 1467-8551.12536

Koonin LM (2020) Novel coronavirus disease (COVID-19) outbreak: Now is the time to refresh pandemic plans. J Bus Contin Emer Plan 13(4):1-15

Kouhizadeh M, Saberi S, Sarkis J (2021) Blockchain technology and the sustainable supply chain: Theoretically exploring adoption barriers. Int J Prod Econ 231:107831

Kuei CH, Madu CN, Lin C (2001) The relationship between supply chain quality management practices and organizational performance. Int J Qual Reliab Manag 18(8):864-872

Kuei CH, Madu CN, Lin C, Chow WS (2002) Developing supply chain strategies based on the survey of supply chain quality and technology management. Int J Qual Reliab Manag 19(7):889-901

Kuhn KD (2018) Using structural topic modeling to identify latent topics and trends in aviation incident reports. Transp Res Part C Emerg Technol 87:105-122

Kumar PS, Anbanandam R (2020) Theory building on supply chain resilience: a SAP-LAP analysis. Glob J Flex Syst Manag 21(2):113-133

Kuo TC, Chen KJ, Shiang WJ, Huang PB, Otieno W, Chiu MC (2021) A collaborative data-driven analytics of material resource management in smart supply chain by using a hybrid Industry 3.5 strategy. Resour Conserv Recycl 164:105160

Kwak DW, Seo YJ, Mason R (2018) Investigating the relationship between supply chain innovation, risk management capabilities and competitive advantage in global supply chains. Int J Oper Prod Manag 38(1):2-21. https://doi.org/10.1108/ IJOPM-06-2015-0390

Kwon O, Lee N, Shin B (2014) Data quality management, data usage experience and acquisition intention of big data analytics. Int $\mathrm{J}$ Inf Manage 34(3):387-394

Lahri V, Shaw K, Ishizaka A (2021) Sustainable supply chain network design problem: Using the integrated BWM, TOPSIS, possibilistic programming, and $\varepsilon$-constrained methods. Expert Syst Appl 168:114373

Lalmi A, Fernandes G, Souad SB (2021) A conceptual hybrid project management model for construction projects. Procedia Comput Sci 181:921-930

Lechler S, Canzaniello A, Roßmann B, Heiko A, Hartmann E (2019) Real-time data processing in supply chain management: revealing the uncertainty dilemma. Int J Phys Distrib Logist Manag 49(10): 1003-1019

Lee J, Kang JH, Jun S, Lim H, Jang D, Park S (2018) Ensemble modeling for sustainable technology transfer. Sustainability 10(7):2278

Majumdar A, Shaw M, Sinha SK (2020) COVID-19 debunks the myth of socially sustainable supply chain: A case of the clothing industry in South Asian countries. Sustain Prod Consum 24:150-155

Mehrotra S, Rahimian H, Barah M, Luo F, Schantz K (2020) A model of supply-chain decisions for resource sharing with an application to ventilator allocation to combat COVID-19. Nav Res Logist (NRL) 67(5):303-320

Mollenkopf DA, Ozanne LK, Stolze HJ (2020) A transformative supply chain response to COVID-19. J Serv Manag 68:143-149

Mousavi SM, Bahreininejad A, Musa SN, Yusof F (2017) A modified particle swarm optimization for solving the integrated location and inventory control problems in a two-echelon supply chain network. J Intell Manuf 28(1):191-206. https://doi.org/10.1007/ s10845-014-0970-z

Nagar D, Raghav S, Bhardwaj A, Kumar R, Singh PL, Sindhwani R (2021) Machine learning: Best way to sustain the supply chain in the era of industry 4.0. Mater Today Proc (In Press). https:// doi.org/10.1016/j.matpr.2021.01.267

Nayal K, Raut RD, Queiroz MM, Yadav VS, Narkhede BE (2021) Are artificial intelligence and machine learning suitable to tackle the COVID-19 impacts? An agriculture supply chain perspective. Int J Logist Manag. https://doi.org/10.1108/IJLM-01-2021-0002

Neto JQF, Bloemhof-Ruwaard JM, van Nunen JA, van Heck E (2008) Designing and evaluating sustainable logistics networks. Int $\mathrm{J}$ Prod Econ 111(2): 195-208

Nitsche AM, Schumann CA, Franczyk B (2021) A Conceptual Reference Framework for Data-driven Supply Chain Collaboration. In Proceedings of the 23rd International Conference on Enterprise Information Systems (ICEIS 2021) - Vol 2, pp 751-758

Ojha R, Ghadge A, Tiwari MK, Bititci US (2018) Bayesian network modelling for supply chain risk propagation. Int J Prod Res 56(17):5795-5819

Pamucar D, Yazdani M, Obradovic R, Kumar A, Torres-Jiménez M (2020) A novel fuzzy hybrid neutrosophic decision-making approach for the resilient supplier selection problem. Int J Intell Syst 35(12):1934-1986

Papadopoulos T, Gunasekaran A, Dubey R, Altay N, Childe SJ, Fosso-Wamba S (2017) The role of Big Data in explaining disaster resilience in supply chains for sustainability. J Clean Prod 142:1108-1118

Paul SK, Chowdhury P (2020) A production recovery plan in manufacturing supply chains for a high-demand item during COVID-19. Int J Phys Distrib Logist Manag 51(2):104-125

Pazhani S, Ventura JA, Mendoza A (2016) A serial inventory system with supplier selection and order quantity allocation considering transportation costs. Appl Math Model 40(1):612-634

Pishvaee MS, Razmi J (2012) Environmental supply chain network design using multi-objective fuzzy mathematical programming. Appl Math Model 36(8):3433-3446

Ponomarov SY, Holcomb MC (2009) Understanding the concept of supply chain resilience. Int J Logist Manag 20(1):124-143

Rahman T, Taghikhah F, Paul SK, Shukla N, Agarwal R (2021) An Agent-Based Model for Supply Chain Recovery in the Wake of the COVID-19 Pandemic. Comput Ind Eng 158:107401

Rajesh R (2020) A grey-layered ANP based decision support model for analyzing strategies of resilience in electronic supply chains. Eng Appl Artif Intell 87:103338

Reeves M, Whitaker K (2020) A guide to building a more resilient business. Harvard Business Review, 2-8

Render B, Stair Jr, RM (2017) Quantitative Analysis for Management, 13e. Pearson Education

Riahi R, Li K, Robertson I, Jenkinson I, Bonsall S, Wang J (2014) A proposed decision-making model for evaluating a container's security score. P I Mech Eng M-J Eng 228(1):81-104

Roberts ME, Stewart BM, Tingley D (2019) Stm: An R package for structural topic models. J Stat Softw 91(1):1-40

Rowe WD (1980) Risk assessment approaches and methods. In: Con$\operatorname{rad} \mathrm{J}(\mathrm{ed})$ Society. Academic Press, London, Technology and Risk Assessment, p 343

Sabbaghi MM (2020) A Supplier Selection Model Emphasizing the Project Risk Management in Drug Production in Pharmaceutical Industry. Tehnički Glasnik 14(2):111-120

Sadeghi A, Doumari SA, Dehghani M, Montazeri Z, Trojovský P, Ashtiani HJ (2021) A New, "Good and Bad Groups-Based Optimizer" for Solving Various Optimization Problems. Appl Sci 11(10):4382

Sayyadi R, Awasthi A (2020) An integrated approach based on system dynamics and ANP for evaluating sustainable transportation policies. Int J Syst Sci Oper Logist 7(2):182-191 
Shahed KS, Azeem A, Ali SM, Moktadir MA (2021) A supply chain disruption risk mitigation model to manage COVID-19 pandemic risk. Environ Sci Pollut Res. https://doi.org/10.1007/ s11356-020-12289-4

Shamsuzzoha A, Ndzibah E, Kettunen K (2020) Data-driven sustainable supply chain through centralized logistics network: Case study in a Finnish pharmaceutical distributor company. Current Research in Environmental Sustainability 2:100013. https://doi.org/10.1016/j. crsust.2020.100013

Sharma A, Rana NP, Nunkoo R (2021) Fifty years of information management research: A conceptual structure analysis using structural topic modeling. Int J Inf Manag 58:102316

Shih WC (2020) Global supply chains in a post-pandemic world. Harv Bus Rev 98(5):82-89

Shishodia A, Verma P, Dixit V (2019) Supplier evaluation for resilient project driven supply chain. Comput Ind Eng 129:465-478

Siderska J, Jadaan KS (2018) Cloud manufacturing: a service-oriented manufacturing paradigm. A review paper. Eng Manag Prod Serv 10(1):22-31

Sindhwani R, Mittal VK, Singh PL, Aggarwal A, Gautam N (2019) Modelling and analysis of barriers affecting the implementation of lean green agile manufacturing system (LGAMS). BIJ 26(2):498-529

Singh S, Ghosh S, Jayaram J, Tiwari MK (2019) Enhancing supply chain resilience using ontology-based decision support system. Int J Comput Integr Manuf 32(7):642-657

Song DP, Dong JX, Xu J (2014) Integrated inventory management and supplier base reduction in a supply chain with multiple uncertainties. Eur J Oper Res 232(3):522-536

Spieske A, Birkel H (2021) Improving supply chain resilience through industry 4.0: a systematic literature review under the impressions of the COVID-19 pandemic. Comput Ind Eng 158:107452

Sun J, Matsui M, Yin Y (2012) Supplier risk management: An economic model of P-chart considered due-date and quality risks. Int J Prod Econ 139(1):58-64

Tang CS (2006) Perspectives in supply chain risk management. Int J Prod Econ 103(2):451-488

Tang O, Musa SN (2011) Identifying risk issues and research advancements in supply chain risk management. Int $\mathbf{J}$ Prod Econ 133(1):25-34

Taqi HM, Ahmed HN, Paul S, Garshasbi M, Ali SM, Kabir G, Paul SK (2020) Strategies to manage the impacts of the COVID-19 pandemic in the supply chain: implications for improving economic and social sustainability. Sustainability 12(22):9483

Tasleem M, Khan N, Nisar A (2019) Impact of technology management on corporate sustainability performance. Int J Qual Reliab Manag 36(9):1574-1599

Tchanche B (2021) Dynamics of Greenhouse Gas (GHG) Emissions in the Transportation Sector of Senegal. Earth 2(1):1-15

Thunberg M, Rudberg M, Gustavsson TK (2017) Categorising on-site problems: A supply chain management perspective on construction projects. Constr Innov 17(1):90-111. https://doi.org/10.1108/ ci-10-2015-0059

Tjahjono B, Esplugues C, Ares E, Pelaez G (2017) What does industry 4.0 mean to supply chain? Procedia Manuf 13:1175-1182

Tranfield D, Denyer D, Smart P (2003) Towards a methodology for developing evidenceinformed management knowledge by means of systematic review. Br J Manag 14(3):207-222
Vinodh S, Antony J, Agrawal R, Douglas JA (2020) Integration of continuous improvement strategies with Industry 4.0: a systematic review and agenda for further research. TQM J 33(2):441-472

Wang CN, Nguyen NAT, Dang TT, Lu CM (2021) A compromised decisionmaking approach to third-party logistics selection in sustainable supply chain using fuzzy AHP and fuzzy VIKOR methods. Mathematics 9(8):886. https://doi.org/10.3390/math9080886

Wang X, Wong TN, Fan ZP (2013) Ontology-based supply chain decision support for steel manufacturers in China. Expert Syst Appl 40(18):7519-7533

Wanke P, Alvarenga H, Correa H, Hadi-Vencheh A, Azad MAK (2017) Fuzzy inference systems and inventory allocation decisions: Exploring the impact of priority rules on total costs and service levels. Expert Syst Appl 85:182-193

Wei X, Prybutok V, Sauser B (2021) Review of supply chain management within project management. Project Leadership and Society 2:100013

Wichmann P, Brintrup A, Baker S, Woodall P, McFarlane D (2020) Extracting supply chain maps from news articles using deep neural networks. Int J Prod Res 58(17):5320-5336

Wong CW, Lirn TC, Yang CC, Shang KC (2020) Supply chain and external conditions under which supply chain resilience pays: An organizational information processing theorization. Int J Prod Econ 226:107610

Wu DD, Zhang Y, Wu D, Olson DL (2010) Fuzzy multi-objective programming for supplier selection and risk modeling: A possibility approach. Eur J Oper Res 200(3):774-787

Wu L, Yue X, Jin A, Yen DC (2016) Smart supply chain management: a review and implications for future research. Int J Logist Manag 27(2):395-417

Wu Y, Lu R, Yang J, Xu F (2021) Low-carbon decision-making model of online shopping supply chain considering the $\mathrm{O} 2 \mathrm{O}$ model. J Retail Consum Serv 59:102388

Xie H, Zhang Y, Wu Z, Lv T (2020) A bibliometric analysis on land degradation: Current status, development, and future directions. Land 9(1):28

Yoon J, Talluri S, Yildiz H, Ho W (2018) Models for supplier selection and risk mitigation: a holistic approach. Int J Prod Res 56(10):3636-3661

Yu W, Chavez R, Jacobs MA, Feng M (2018) Data-driven supply chain capabilities and performance: A resource-based view. Transport Res E-Log 114:371-385. https://doi.org/10.1016/j.tre.2017.04.002

Zahedi A, Salehi-Amiri A, Smith NR, Hajiaghaei-Keshteli M (2021) Utilizing IoT to design a relief supply chain network for the SARSCOV-2 pandemic. Appl Soft Comput 104:107210

Zhang F, Wu X, Tang CS, Feng T, Dai Y (2020) Evolution of Operations Management Research: from Managing Flows to Building Capabilities. Prod Oper Manag 29(10):2219-2229

Zuo K, Potangaroa R, Wilkinson S, Rotimi JO (2009) A project management prospective in achieving a sustainable supply chain for timber procurement in Banda Aceh, Indonesia. Int J Manag Proj Bus 2(3):386-400

Publisher's Note Springer Nature remains neutral with regard to jurisdictional claims in published maps and institutional affiliations. 